\title{
Über Strukturen in den Zellen des embryonalen Stützgewebes sowie über die Entstehung der Binde= gewebsfibrillen, insbesondere derjenigen der Sehne.
}

Von

Friedrich Meves in Kiel.

Hierzu Tafel II und III.

I. Einleitung.

Inhalt.

II. Material und Methode der Untersuchung.

III. Strukturen in den Zellen des embryonalen Stützgewebes.

A. Eigene Beobachtungen.

1. . Bindegewebszellen.

2. Knorpelzellen, Osteoblasten und Knochenzellen.

B. Literatur.

1. Bindegewebszellen.

2. Knorpelzellen.

3. Osteoblasten und Knochenzellen.

IV. Über die Entstehung der Bindegewebsfibrillen.

A. Eigene Beobachtungen an der Sehne.

B. Literatur.

1. Literatur über Sehnenentwicklung.

2. Literatur über Entstehung der Bindegewebsfibrillen im allgemeinen.

a) Aus der älteren Literatur von $\mathrm{Sch}$ wann bis Flemming.

b) Neuere Literatur von Flemming bis heute.

a) Die Bindegewebsfibrillen entstehen durch Umwandlung von Protoplasmafortsätzen (Zachariadès, v. Szily).

i) Die Bindegewebsfibrillen sind Umbildungen einer cytoplasmatischen Struktur (Flemming, Reinke, Waldeyer, Spuler, Studnicka, Hansen, Spalteholz u. a.).

y) Die Bindegewebsfibrillen entstehen aus einer von den Zellen gebildeten formlosen Substanz (Merkel, v. Ebner, Retterer, Mall, Renaut, Laguesse,

V. Schluss. Bruni). 


\section{Einleitung.}

In einer im vorigen Jahre (1908) erschienenen Arbeit habe ich gezeigt, dass in sämtlichen Zellen junger Embryonen Chondriosomen vorhanden sind, welche entweder als Körner, Mitochondrien, oder aber, und zwar der Regel nach, als Faden, Chondrioconten, auftreten.

Von diesen Chondriosomen habe ich behauptet, dass sie allen Iifferenzierungsprozessen, welche sich bei der Sonderung des Embryonalleibs in verschiedene Organe und Gewebe abspielen, als das materielle Substrat, welches in die verschiedenen spezifischen Substanzen umgewandelt wird, zugrunde liegen. $\mathrm{Zu}$ den Differenzierungsprodukten der Chondriosomen gehören, wie ich ausgeführt habe, erstens die verschiedenen Faserstrukturen, zahlreiche fibrillare Bildungen in Epithelzellen, wie z. B. die „Proto.plasmafasern" der Epidermiszellen, die Fibrillen der glatten und quergestreiften Muskelfasern, die Neurofibrillen und Neurogliafasern, die Bindegewebsfasern; zweitens wahrscheinlich auch die verschiedensten auffulligen $\mathrm{chemischen} \mathrm{Erzeugnisse} \mathrm{des} \mathrm{cellularen}$ Stoffwechsels, wie z. B. die Sekretkörner, das Fett, die Pigmentund Dotterkörner.

Wenn eine derartige Rolle der Chondriosomen in der Histogenese tatsächlich nachgewiesen wäre, würde es vielleicht angemessen sein, sie in der Bezeichnung zum Ausdruck zu bringen; man könnte statt von Chondriosomen von Plastosomen (Plastochondrien, Plastochondriomiten oder kürzer Chondriomiten, Plastoconten) sprechen.

Duesberg hat bereits in diesem Jahr (1909) die Existenz von Chondriosomen in sămtlichen embryonalen Zellen bestätigt; er hat ferner ihr späteres Schicksal bei der Entstehung der quergestreiften Muskelfasern studiert und ist dabei zu dem Schluss gekommen, dass sie ${ }_{n}$ tatsächlich, wie Meves schreibt, zu Myofibrillen verwendet werden".

In der vorliegenden Arbeit will ich zunächst zeigen, dass die Chondriosomen in sämtlichen Zellen des Stützgewebes beim Embryo späterer Stadien gegenwărtig sind. Sodann will ich einen Teil derjenigen Beobachtungen schildern, welche mir als Grundlage für meine Behauptung gedient haben, dass die Chondriosomen das Bildungsmaterial für die $\mathrm{B}$ indegewe $\mathrm{b}$ sfasern abgeben. 


\section{Material und Methode der Untersuchung.}

Die vorliegende Untersuchung habe ich an Hühnerembryonen, und zwar an den unteren Extremitaten derselben, angestellt, welche ich vom Embryonalkörper durch einen Scheerenschnitt oberhalb des Hüftgelenks abgetrennt und mit Flemming schem Gemisch von der früher gebrauchten Zusammensetzung ( $1 / 2 \%$ ige Chromsüure mit Zusatz von $1 \%$ Kochsalz $15 \mathrm{ccm}, 2 \%$ ige Osmiumsäure $3-4 \mathrm{ccm}$, Eisessig 3-4 Tropfen) fixiert habe. Hühnerembryonen habe ich nicht nur wegen der Leichtigkeit verwandt, mit welcher sie zu beschaffen sind, sondern auch deshalb, weil sie mir für die Zwecke meinerUntersuchung besonders geeignet schienen. Embryonen von Kaninchen und Meerschweinchen bieten dem Hühnchen gegenüber jedenfalls keine Vorteile, da ihre Zellen eher feinere als stärkere Chondrioconten enthalten. Auch bei der Salamanderlarve sind die Fäden, wenigstens in den meisten Zellarten, feiner als beim Hühnerembryo, trotzdem das erstere Tier den Vorzng hat, sehr viel grössere Zellen zu besitzen.

Die Extremitaten habe ich aus dem Grunde als Untersuchungsobjekt gewählt, weil sie, wenigstens noch bei $8-9$ Tage alten Embryonen, von sämtlichen Bestandteilen Flemmingschen Gemisches von der empfohlenen Zusammensetzung ziemlich vollständig durchdrungen werden. Das ist deshalb von Wichtigkeit, weil die Chondriosomen durch das Flemmingsche Gemisch nur so weit gut konserviert werden, wie die Wirkung der Osmiumsäure reicht. Im Innern grösserer Objekte dagegen, in welches nur die beiden anderen Säuren eindringen, sind sie, wenn überhaupt noch erkennbar, nur höchst mangelhaft erhalten. Die Chondrioconten haben sich hier mehr oder weniger stark verkürzt, daneben häufig der Quere nach fragmentiert. Die auf diese Weise entstandenen Kügelchen können weiter ibrerseits ebenso wie etwa vorhandene Mitochondrien zu hellen Bläschen aufgequollen sein. Bei den Extremitäten älterer Hühnerembryonen habe ich daher, wenn es mir auf eine gute Fixierung der tieferen Teile ankam, diese dadurch $\mathrm{zu}$ erreichen gesucht, dass ich vorher die Haut mit Hilfe einer Pinzette abzog.

Zur Färbung der Chondriosomen habe ich wieder in erster Linie die Eisenhämatoxylinmethode nach M. Heidenhain angewandt, bei deren Handhabung ich in der früher (1907, 1, S. 417) beschriebenen Weise verfahren bin. 
Die jungen Bindegewebsfibrillen geben bei dem Extraktionsverfahren das Hämatoxylin gewöhnlich leicht ab. Um sie tingiert zu erhalten, habe ich die mit Eisenhämatoxylin vorgefärbten Prăparate einer Nachfärbung mit Fuchsin S unterworfen. Diese habe ich gewöhnlich in der Weise ausgeführt, dass ich einige Kubikzentimeter einer vorrïtig gehaltenen $2 \%$ igen wässerigen Lösung von Fuchsin S dem 95\% igen Alkohol, welcher mir zur ersten Entwässerung diente, hinzufügte. Nachdem die Schnitte in dieser Farblösung 1-2 Minuten verweilt hatten, wurde der überschüssige Farbstoff mit reinem $95 \%$ igem Alkohol abgespült; weiter wurde in Alkohol absolut., Xylol, Canadabalsam übertragen.

\section{Strukturen in den Zellen des embryonalen Stützgewebes.}

A. Eigene Beobachtungen.

Die Gliedmaßen eines drei- bis viertägigen Hühnerembryos bestehen aus einer dichtgedrüngten Masse kleiner sternförmiger Zellen, deren spärliches Cytoplasma geschlängelte Chondriconten einschliesst.

Am fünften und sechsten Tage setzen sich in der ursprünglich gleichartigen Zellenmasse zuerst die Anlagen der verschiedenen Gewebe voneinander ab. Die Chondrioconten bleiben dabei überall erhalten. Von ihrem Vorhandensein in den sämtlichen Zellarten des Stützgewebes bei älteren Embryonen bitte ich den Leser sich an der Hand der Tafel II zu überzeugen.

1. Bindegewebszellen (Fig. 1-10; teilweise auch Fig. 15).

Fig. 1 stammt ans einem Schnitt durch die untere Extremität eines sechstägigen Embryos. Unter dem Ectoderm (links) liegen, in Abständen voneinander, sternförmige Zellen, welche teilweise mit ihren Ausläufern zusammenhängen. Sie enthalten stark gekrümmte und geknickte Fáden, deren in verschiedenen Ebenen gelegenen Windungen man meistens durch Bewegung der Mikrometerschraube folgen kann. Daneben finden sich auch Körner, Mitochondrien; die meisten Körner, welche man in den Zellen sieht, sind aber wirkliche oder optische Querschnitte von Fäden.

Fig. 2, von demselben sechstägigen Embryo, ist ein Schnitt durch die Randpartie einer Sehne, welche aus länglichen Zellen besteht, deren Cytoplasma kurze Fadenstücke einschliesst. 
Fig. 3 gibt einen Teil eines Querschnitts durch den Unterschenkel eines achttägigen Hühnerembryos wieder. Unmittelbar unter dem Ectoderm ist die Lederhaut aufgetreten. Sie besteht aus dicht beisammenliegenden, spindelförmigen Zellen, welche mit ilırer Laangsachse der Regel nach senkrecht zu derjenigen der Extremität gestellt sind, sodass sie auf einem Querschnitt durch die Extremität der Lange nach getroffen werden. Die Chondriokonten verlaufen in der Längsrichtung der Zellen. An diese dichte Zellage schliesst sich nach unten eine mehr lockere Schicht an, welche eine "blätterteigartige" Beschaffenheit hat. Die meisten Cytoplasmastrünge, welche man in Fig. 3 unter der Lederhaut wahrnimmt, sind nämlich, wie man durch Heben und Senken des Tubus feststellen kann, nicht solche, sondern optische Qnerschnitte von sehr dünnen Blittern. Dieser lamelläre Bau wird weiter nach unten zu immer ausgesprochener. In seinen tietsten Partien entspricht der Schnitt wohl der Anlage einer oberflachlichen Fascie und besteht aus ciner grossen Anzahl von tinander parallelen, wenn auch etwas faltigen Lamellen, welche dicht übereinander liegen. Diese Lamellen setzen sich aus scheibenförmigen dünnen Zellen zusammen, deren Grenzen nicht erkennbar sind. Die Zellen schliessen Kerne ein, welche, obwohl ebenfalls mehr oder weniger stark abgeplattet, dennoch eine relativ erhebliche Verdickung der Zellenleiber bedingen. Die verdickten Zellpartien in der Nachbarschaft der Kerne enthalten ausser einer dunkeln körnigen Masse, auf welche ich unten zurückkomme, stets zahlreichere Chondrioconten; vereinzelte solche, quer-, schräg- und längsgeschnitten, triffit man überall in den Lamellen oder Zellen.

Fig. 4 ist ein Flachschnitt durch die tiefere Lage des Coriums vom Mittelfuss eines zehntägigen Embryos. Von den Zellen dieser Abbildung, welche kürzere und längere Fäden enthalten, befindet sich eine in Teilung, und zwar auf dem Stadium des Muttersterns.

In meiner frïheren Arbeit (1908) habe ich angegeben, dass in den Zellen des Hühnerembryos der Ablauf einer Nitose auf das Verhalten und die Lagerung der Chondriosomen gänzlich ohne Einfluss zu sein scheine. In der Tat bleiben in vielen Fällen, speziell bei jüngeren Embryonen vom ersten bis vierten Tag, die Chondriosomen bis zum völligen Abschluss der Teilung Archir f. mikr. Anat. Bd. 75. 
unregelmüssig im Zelleib verteilt. In anderen Fallen aber, besonders bei älteren Embryonen, beobachtet man folgendes Verhalten (man vergl. die Fig. 5 a-e, welche aus dem Corium vom Mittelfuss eines zehntägigen Embryos stammen): Auf dem Stadium des Muttersterns liegen die Chondrioconten, um welche es sich hier durchweg handelt, im Limkreis der Teilungsfigur verstreut (Fig. 5 a). Auf dem Stadium des Doppelsterns umgeben sie tonnenförmig die Spindel zwischen den Tochterchromosomen, während sie die Spindelpole freilassen (Fig. 5b). Nach diesem Stadium sammeln sie sich in dem Raum $z$ wischen den beiden Chromosomengruppen (Fig. 5c). Dabei scheinen sie vielfach in kürzere Stücke zu zerfallen oder auch stärker gewundene und geknickte Formen, als sie vorher hatten, anzunehmen. Bei der Zelldurchschnürung wird die Masse der Chondrioconten wie der ganze Zelleib selbst sanduhrförmig durchgeteilt (Fig. 5d). In beiden Tochterzellen liegt je ein Komplex von Chondrioconten auf den äquatorialen Seiten der Tochterkerne (Fig. 5 e).

Wahrscheinlich soll durch das beschriebene Ferhalten der Chondrioconten eine gleichmässigere Verteilung derselben auf die Tochterzellen erreicht werden.

Fig. 6-8 sind nach Flachschnitten vom Unterschenkel eines zehntägigen Embryos gezeichnet; sie stellen Stücke von Zelllamellen des Subcutangewebes bezw. einer obertlachlichen Fascie in Flächenansicht dar. In Fig. 8 befindet sich der Kern in Mitose.

Das in Fig. 6 abgebildete Lamellenstück enthült drei Kerne. Zellgrenzen sind ebensowenig wie in der Kantenansicht (Fig. 3) erkennbar. Neben jedem Kern nimmt man die vorhin schon erwahnte dunkle Masse wahr, welche offenbar die Centriolen einschliesst, also als "Centrotheca" aufzufassen ist. In der Umgebung der Centrotheca liegen Chondrioconten, die zum Teil ziemlich lang sind und nicht selten (Fig. 7) eine deutlich radiäre Anordnung um diese herum aufweisen. Vereinzelt finden sich Chondrioconten auch weiter von der Centrotheca entfernt. In nächster Nachbarschaft der letzteren liegen im Cytoplasma ausser den Chondriconten noch kleine helle Vacuolen, weiter entfernt davon gewahrt man grössere.

In Fig. 9 und 10 habe ich zwei lang spindelförmige Bindegewebszellen, von welchen die eine in Mitose ist, aus der tieferen Schicht des Coriums von einem vierzehntägigen Hühnerembryo 
abgebildet. Bei beiden Zellen sind Chondrioconten, welche eine besondere Länge aufweisen, in den Ausläufern enthalten.

Man beachte schliesslich von Fig. 15, Teil eines Querschnitts durch einen Metatarsus eines zehntägigen Embryos, schon jetzt die Zellen des Periosts, welche Chondrioconten enthalten, die parallel der Knochenlängsachse verlaufen und daher auf einem Querschnitt ebenfalls der Quere nach getroffen sind.

Während die Chondrioconten jüngerer Bindegewebszellen zweifellos im Innern des Cytoplasmas liegen, sieht man später zahlreiche Fïden, welche auf die Zelloberflache verlagert sind. $O b$ die Fäden eine intra- oder epicelluläre Lage haben, lässt sich am sichersten entscheiden, wenn sie, wie in Fig. 15, in den Zellen des Periosts, der Quere nach getroffen sind.

Das Epicellulärwerden der Chondrioconten bedeutet, wie wir später sehen werden, den Anfang zu ihrer Umwandlung in Bindegewebstasern.

2. Knorpelzellen (Fig. 11-14), Osteoblasten und Knochenzellen (Fig. 15, 16 und 28).

Die gleichen Fäden, wie in den Zellen des Bindegewebes, finden sich auch in Knorpelzellen, Osteoblasten und Knochenzellen, und zwar im allgemeinen unregelmässig durch den Zelleib verteilt.

In embryonalen Knorpelzellen sind zuerst von Van der Stricht, in Osteoblasten von Spuler Centriolen beschrieben worden, welche von einem abgegrenzten Hof, einer Sphäre oder Centrotheca, umgeben sind. In meinen Figuren von Knorpelzellen sind nur die Centrothecen, nicht aber die Centriolen, welche nicht herausgefärbt sind, zu sehen; ebenso in den Osteoblasten der Fig. 28, welche nach einem mit Säurefuchsin nachgefärbten Priparat gezeichnet ist. In den Osteoblasten und Knochenzellen von Fig. 15 und 16 dagegen ist auch von den Centrothecen nichts wahrzunehmen. Jedoch erkennt man in mehreren Knochenzellen der Fig. 16 eine von Chondrioconten freigelassene Stelle, welche augenscheinlich von der Centrotheca eingenommen wird.

Gar nicht selten sieht man sowohl in Knorpelzellen wie in Osteoblasten einzelne Chondrioconten mit ihrem einen Ende in die Centrotheca eindringen, um entweder in ihr $\mathrm{zu}$ endigen oder 
an einer anderen Stelle wieder auszutreten. Kürzere Füden sind zuweilen ganz von Centrothecasubstanz umschlossen. ${ }^{1}$ )

\section{B. Literatur.}

Einer Zellstruktur kann man, wie Fle mming nicht müdewurde zu betonen, „nur da ganz sicher sein, wo an der lebenden oder frischen Zelle sich ein deutlicher Ausdruck des durch Reagentien dargestellten ergibt"; im übrigen darf man "höchstens nach Analogie schliessen" (1895, S. 361).

Nun habe ich gezeigt, dass die Fila, welche Flemming (1882) in lebenden Salamanderzellen beobachtet hat, durch die (hondriosomenmethoden darstellbar und mit Chondrioconten identisch sind. Daraus ergibt sich, dass die ähnlichen Fadenstrukturen, welche durch die gleichen Methoden bei anderen $\mathrm{Ob}$ jekten erhalten werden, ebenfalls Filarmasse im Sinne Flemmings ieprisentieren und dass an ihrer Vitalitit nicht zu zweifeln ist. Die Fäden (Chondrioconten) können auch in Form von fö̈nern (Mitochondrien) vorkommen. Fäden und Körner sind zwei verschiedene Erscheinungsformen einer und derselben Substanz.

\section{Bindegewebszellen.}

Flemming konnte 1882 einen Fadenbau an den lebendigen: verästelten Bindesubstanzzellen der Salamanderlarve an dünnen und bellen Orten der Schwanzflosse, am besten aber am ganz. frisch aufgelegten Kiemenblatt, erkennen. Jedoch rermag er das Bild nicht sehr scharf zu nennen; „eine weitere Verfolgung einzelner Fäden oder gar die Entscheidung, dass das ganze ein zusammenhängendes Netzwerk sei", muss er unmöglich finden.

Auf das gleiche Objekt ist Flemming spater in zwei Arbeiten aus dem Jahre 1897 zurückgekommen. In der ersten Arbeit „über den Bau der Bindegewebszellen und Bemerkungen ïber die Struktur der Zellsubstanz im allgemeinen" sagt er mit Bezug auf die Bindegewebszellen des Kiemenblatts bei jüngeren Salamanderlarven: "Man sieht (im frischen Zustand) am Zell-

1) Durch Eisenhämatoxylin schwarz färbbare Stäbe oder Fäden, welche in die "Sphäre* eindringen oder sie durchsetzen, habe ich schon 1896 (S. 34) in ruhenden Spermatocyten (Auxocyten) von Salamandra beschrieben und in den Figg. 42 und 45-47 abgebildet; eine Deutung dieser Bildungen wusste ich damals nicht zu geben. 
körper und seinen grösseren Ausläufern nichts anderes als hier und da eine sehr zarte, verwaschene Längsstreifung. An ungefürbten Präparaten aus Chromosmiumessigsäure erscheint diese Streifung viel deutlicher." „Es ist zu vermuten ", fährt er fort, „dass sie mit der fibrillenbildenden Tätigkeit dieser Zellen in Beziehung steht und die in ihrer Peripherie belegenen ersten Anlagen der collagenen Füserchen darstellt."

$\mathrm{Zu}$ diesem letzteren Satz ist zu bemerken, dass die Chondrioconten zunächst durchaus nicht ausschliesslich ,in der Peripherie belegen", sondern durch den ganzen Zelleib verteilt sind.

In der zweiten Abhandlung desselben Jahres hat Flemming die gleichen Faden an Kiemenblättern älterer Larven nach Fixierung mit seinem Gemisch durch Färbung mit Hümatoxylin dargestellt; er beschreibt durchaus zutreffend, dass sie hier in den Ausliufern oder an ihnen gelagert sind, hat sie aber nicht als die cytoplasmatischen Fila, welche er bereits am frischen Präparat gesehen hatte, wiedererkannt, sondern als Bindegewebsfibrillen angesprochen. Näheres hierüber siehe unten.

Fadenstrulituren in Bindegewebszellen sind noch von einer Reihe anderer Autoren beschrieben worden; aber es ist bisher wolnl kaum gelungen, dieselben so allgemein und in so scharfor Weise darzustellen, wie ich es beim Hühnerembryo vermocht habe.

$\mathrm{Vacuolen}$, wie ich sie in den Zellen des Unterhautbindegewebes beim Hühnchen gefunden habe, sind schon früher von Unna und Flemming in Bindegewebszellen gesehen worden. Un na hat 1895 bei menschlichen Bindegewebszellen aus pathologischen Geweben, besonders Granulationen, nach Alkoholfixierung, die von einer Färbung mit polychromem Methylenblau gefolgt war, einen Wabenbau der Zellsubstanz beschrieben. Fle m ming $(1897,1)$, welcher die Resultate Unnas an normalen Bindegewebszellen der Salamanderlarve nachgeprüft hat, findet diese bei Anwendung der Unnaschen Methode fast genau so aussehend wie Unnas menschliche Zellen. An Präparaten dagegen, die mit Chromosmiumessigsăure fixiert und mit Eisenhämatoxylin stark gefärbt sind, sind die Vacuolen in ihnen unverkennbar bedeutend kleiner und spärlicher, aber doch ohne Zweifel vorhanden; allerdings so, dass Flemming nicht gerade von einem Wabenbau reden möchte, sondern von einer ziemlich stark, aber unregelmässig vakuolisierten Zellsubstanz. - Meine eigenen Beobachtungen an 
den Zellen der subkutanen Lamellen des Hühnerembryos stimmen am meisten mit denjenigen Flemmings überein.

2. Knorpelzellen.

Über Strukturen der Knorpelzellen existiert eine grosse Literatur, welche ich hier nur oberflächlich berühren kann.

Am bekanntesten ist die Darstellung geworden, welche Flemming von der Struktur der Knorpelzelle der Salamanderlarve gegeben hat. Nach Flemming schliesst das Cytoplasma Fïden ein, welche in Zellen, die der Knorpeloberflïche zunächst liegen, vielfach im ganzen konzentrisch zum Kern angeordnet sind, in der Mitte der Knorpel aber meist keine solche Regel der Anordnung zeigen.

Dass ich die von mir in den Knorpelzellen des Hübnchens dargestellten Füden als identisch mit den Flem mingschen Fila betrachte, bedarf keines Hinweises mehr.

Ein nach der Be ndaschen Chondriosomenmethode gefürbtes Präparat von Knorpelzellen des Hühnerembryos, welche lange Chondrioconten zeigten, hat $\mathrm{Du}$ esberg auf der diesjälrigen Versammlung der anatomischen Gesellschaft in Giessen (1909) demonstriert; nach privater Mitteilung hat er die Chondrioconten auch in den lebenden Knorpelzellen des Hühnchens deutlich sichtbar gefunden, was ich auf Grund eigener Wahrnehmung bestätigen kann.

Die gleichen Fäden sind schon früher an Reagentienpräparaten von M. Heidenhain, v. Smirnow, wahrscheinlich auch von Loewe $\mathrm{nth}$ al und anderen gesehen worden.

M. Heidenhain (1900) beschreibt in Knorpelzellen der Salamanderlarve "fadenartige Körper", welche er mit anderen, die in den Hodenzellen von Proteus vorkommen (Pseudochromosomen, M. H eid en ha in), zusammenhält.

v. Smirnow (1906) fand in Knorpelzellen von Siredon, welche in Flemmingschem Gemisch fixiert und mit Eisenhämatoxylin tingiert waren, „schwarz gefärbte fadenförmige Gebilde, die bald vereinzelt, bald nahe beieinander liegen und in letzterem Falle eine Anhäufung von sich verflechtenden Fäden bildeten."

Loewenthal (1907) entdeckte in den Zellen des caput femoris vom Frosch nach Fixierung mit Flemming schem Ge- 
misch und Färbung mit Hämalaun scharf gezeichnete, geknickte oder gewundene Filden, welche an einer oder an zwei Stellen neben dem Kern zusammengebäuft waren; er ist allerdings der Meinung, dass es sich nicht um die Flemmingschen Fäden, sondern um andere Gebilde handelt, worin ich ihm jedoch nicht beistimmen möchte.

Retterer (1907), welcher den Bau der Knorpelzellen bei Amphibien und Rochen studiert hat, beschreibt, dass ihr zentraler Teil zahlreiche chromophile Granula (Mitochondrien) enthält, die zu Fäden aufgereiht sind.

Arnold (1908) beobachtete beim Frosch in den Zellen des Episternums am lebenden und fixierten Objekt eine paranucleäre Gruppe von Granula, welche in ihrer Anordnung mit den von Loewenthal geschilderten Gebilden "weitgehende Übereinstimmung zeigen". Ich habe selbst den Knorpel von Froschlarven mit Hilfe der Chondriosomenmethode untersucht und gefunden, dass hier (an Präparaten, die mir gut fixiert schienen) tatsächlich ausser kurzen Fädchen hauptsächlich Körner (Mitochondrien) in den Zellen enthalten sind. Bei anderen Tieren tritt aber die Substanz, aus welcher die Körner gebildet sind, ausschliesslich in Form lüngerer Fäden auf; ich kann daher Arnold jedenfalls nicht beiptlichten, wenn er Granula dieser Art als wesentliche Strukturbestandteile des Plasmas der Knorpelzelle überhaupt hinstellt.

Nowik off (1909) suchte auf Anregung von Goldsch midt nach "Chromidien" in den Knorpelzellen von Wirbeltieren, konnte aber hier nichts finden, was er dafür halten möchte. Dagegen entdeckte er im Subradularknorpel einer Kiemenschnecke (Haliotis tuberculata) fast in jeder Zelle neben dem Kern eine mellr oder weniger kompakte körnige Masse, welche in bezug auf ihr Fürbungsvermögen sowohl vom Zellkern, als auch vom Protoplasma zu unterscheiden war und "welche nichts anderes als einen, Chromidialapparat" darstellt". Die Körnchen, welche die Masse bilden, sollen durch Zerfall der Nucleolen entstehen, welche aus dem Kern auswandern.

Ich habe diese Mitteilung von Nowikoff hier deshalb referiert, weil sie beweist, dass die „Chromidien", welche Goldschmidt und andere Münchener Zoologen in Metazoenzellen 
finden wollen, nicht in den Mitochondrien oder Chondriosomen vorliegen können. Auch muss ich jede nachweisbare genetische Beziehung zwischen Chondriosomen und "Chromidien" oder Bestandteilen des Kerns, wie schon früher (1907, 1, S. 479), so auch allen neueren dahin lautenden Angaben gegenüber mit grösster Bestimmtheit in Abrede stellen. Die Fig. B b (nach Jörgensen) auf S. 108 von Goldschmidts letztem Aufsatz (1909), welche den Mitochondrienaustritt aus dem Kern einer Proteusovogonie beweisen soll (das "glanzendste Beispiel", das Goldschmidt "bisher zu Gesicht gekommen ist") halte ich nach eigener Kenntnis zahlreicher ahnlicher Objekte, speziell der Eizellen von Salamandra, für irrtümlich bezw. schematisiert. Hiermit glaube ich meine Stellung zur Goldschmidtschen Lehre vom "Chromidialapparat der Metazoenzelle" genügend gekennzeichnet zu haben.

In früheren Arbeiten lrabe ich es für möglich erklärt, dass die "Netzapparate", welche Golgi und seine Schüler (1898 bis 1909), Pensa (1901) speziell bei Ḱnorpelzellen von Säugetieren, beschrieben haben, mit Chondrioconten identisch sein könnten. Daran glaubte ich unter anderem deshalb denken zu dürfen, weil ich beobachtet hatte, dass netzartige Anordnungen von Chondrioconten tatsächljch vorkommen. Ich habe nun aber neuerdings Knorpelzellen von Embryonen sehr verschiedener Tiere, auch von Kaninchen und Meerschweinchen, unter Anwendung der Chondriosomenmethoden untersucht, habe aber nirgends netzförmige Verbindungen von Chondrioconten beobachtet. Da ich aber nicht annehmen kann, dass diese Strukturen in den Knorpelzellen erwachsener Tiere wesentlich anders angeordnet sein sollten, komme ich zu dem Resultat, dass der "Netzapparat" der Knorpelzellen, wenn er tatsächlich als solcher vital existiert und nicht etwa ein Fixierungsartefakt irgendwelcher Art darstellt, neben den Chondrioconten vorhanden sein und eine von ihnen verschiedene Bildung repräsentieren muss. ${ }^{1}$ )

1) Wie ich einer soeben in den Archives italiennes de Biologie (t. 51, fasc. 2, 1909) erschienenen Abhandlung von Golgi entnehme, hat sich neuerdings auch Perroncito (dem Golgi sich anschliesst) an mir nicht zugänglicher Stelle (Renã. Ist. Lomb. serie $2 \mathrm{a}$, vol. 41) nach Untersuchung an Samenzellen gegen eine Identifizierung von "Netzapparat" und Chondriosomen ausgesprochen. 
Van der Stricht (1892) beschreibt, dass die embryonalen Knorpelzellen ein centriertes "Mitom" (in dem von mir 1907, 2, S. 567 bezeichneten Sinne) besitzen. Die Möglichkeit, dass ein solches in der lebenden Zelle existiert, gebe ich vollkommen zu; ich konnte an meinen Präparaten nicht erwarten, etwas davon wahrzunehmen, weil sich hier überall eine starke Osmiumsăurewirkung geltend macht. Dagegen betrachte ich es als zweifelhaft, ob auch die feinen Netzwerke, welche M. Heidenhain (1900) neben Chondrioconten in Knorpelzellen der Salamanderlarve in Fig. 6 abbildet, vital präformiert sind.

Verschiedene Autoren haben das Cytoplasma der Knorpelzellen als "grobwabig" beschrieben. Ich stehe auch in dieser Beziehung auf dem Standpunkt F le m mings $(1897,1)$, nach welchem grosse Vacuolen in den Knorpelzellen Kunstprodukte sind. Dagegen ist es nach Flemming sebr wahrscheinlich, "dass die Vacuolen in kleinerem Zustand in natura existieren, aus dem Grunde, weil man kleinere Fettkörnchen in den lebenden Knorpelzellen in Molecularbewegung sieht: es kain dies nur erklärt werden, wenn man entweder ein Flüssigsein der ganzen Interfilalmasse oder die Existenz von Hüssigkeitshaltigen Vacuolen in derselben annimmt. In letzterem Fall wïren dies allerdings nicht feine Waben in Bütschlis Sinne, sondern erheblich grössere Hohlräume."

\section{Osteoblasten und Knochenzellen.}

In den Osteoblasten sind von verschiedenen Autoren, z. B. von Van der Stricht (1889, Taf. 2, Fig. 8) und von Spuler (1899, S. 16) Granula gefunden worden; nach letzterem Autor färben sie sich mit Eisenhämatoxylin schwarz und liegen besonders um die Centriolen und die sie umgebenden Höfe angeordnet. "Häufig begegnet man Bildern, bei denen sich die Körner an den feinen Protoplasmafortsätzen der Osteoblasten befinden."

Nach Disse (1909) dagegen besitzen die Osteoblasten beim menschlichen Embryo ein dichtes „feinstreifiges" Protoplasma.

Gewundene Fäden, wie ich sie in den Osteoblasten und Knochenzellen des Hühnchens beschrieben habe, sind bei dieser Zellart meines Wissens bisher nicht gesehen worden. 


\section{IV. Über die Entstehung der Bindegewebsfibrillen.}

A. Eigene Beobachtungen an der Sehne.

Nachdem ich im obigen die Existenz von Chondrioconten in den Zellen des embryonalen Stützgewebes nachgewiesen habe, gehe ich dazu über, diejenigen Bilder zu beschreiben, welche in mir die Überzeugung erweckt haben, dass die Bindegewebsfasern, ebenso wie z. B. die Myo- und Neurofibrillen, funktionell differenzierte Chondrioconten sind, wobei ich mich in der vorliegenden Abbandlung auf ein einziges Objekt, die embryonale Sehne, beschranken will.

Eine Sehne aus der unteren Extremität eines sechstägigen Hühnerembryos (Fig. 2) besteht aus dicht aneinanderliegenden länglichen Zellen, welche mit ihrer Lüngsachse parallel der Achse der Sehne gelagert sind. Die Zellen laufen an ihren Enden meistens. in feine Fortsätze aus. An Sehnenpartien, welche locker gebaut sind, kann man feststellen, dass die hintereinander gelegenen Zellen mittels dieser Fortsitze zusammenhängen; mitunter stehen sie auch durch breitere Protoplasmabrïcken in Verbindung. Der Zellenleib und seine Auslaufer sclliessen bei diesen jüngsten Sehnen meistens nư kürzere Fadenstïcke ein.

Zellen und Kerne nehmen nun weiter an Grösse zu. Fig. 17 stellt einen Teil eines Lüngsschnittes durch eine junge Sehne nahe der Spitze der unteren Extremităt von einem achttägigen Embryo dar; das zugrunde liegende Prïparat ist ebenso wie diejenigen, nach welchen die übrigen Figuren der Tafel gezeichnet sind, nach der Färbung mit Eisenbämatoxylin einer Nachfärbung mit Fuchsin S unterworfen worden. Die Kerne sind etwa auf das doppelte derjenigen Grösse, die sie in Fig. 2 haben, herangewachsen. Die Chondrioconten sind dicker, ausserdem (der Regel nach) auch länger geworden und haben einen mehr geraden Verlauf.

Wenn man sodann die wenig älteren Entwicklungsstadien betrachtet, welche in Fig. 18 und 19 dargestellt sind (aus weiter proximalen Teilen derselben Extremităt, von welcher auch Fig. 17 stanmt), so fallt am meisten auf, dass hier bereits junge Bindegewebsfasern vorhanden sind, welche durch das Fuchsin S stark rot gefärbt sind; in Fig. 18 allerdings nur erst an wenigen Stellen, in Fig. 19 aber schon sehr zahlreich.

Die jüngsten und feinsten Fibrillen liegen den Zellkörpern so dicht an, dass sie mit der Zelloberflăche zusammenfliessen und 
als rot gefärbte Randkonturen der Zelle erscheinen. Die ălteren Fibrillen dagegen verlaufen meist frei zwischen den Zellen. Alle Fibrillen, auch die jüngsten, sind nicht gerade, sondern wellig; und zwar die etwas älteren stärker als die jüngeren.

Freie Endigungen der Fibrillen lassen sich nicht bestimmt nachweisen. Wo solche in den Figurèn vorhanden zu sein scheinen, treten die Fibrillen tatsächlich wohl nur aus der Schnitt- oder Zeichenebene heraus. Wahrscheinlich verlaufen sie von allem Anfang an über weite Strecken kontinuierlich. Mitunter sieht man eine Fibrille, welche eine Strecke weit an einer Zellreihe entlang gezogen ist, auf eine Nachbarreihe überspringen.

Es fragt sich nun, ob die Figuren 18 und 19 sonst noch irgend etwas erkennen lassen, was geeignet wäre, auf die Entstehung der Fibrillen Licht zu werfen. In dieser Beziehung zeigt sich folgendes: Die Chondrioconten, welche schon vorher länger und mehr gerade erschienen, sind zum Teil an die Zelloberfläche verlagert und zwar so, dass ihre Richtung der Längsachse der Sehne parallel ist.

Um die epicelluläre Lage eines Teils der Chondrioconten klar zu erkennen, ist es notwendig, Querschnitte von Sehnen gleicher Stadien wie Fig. 18 und 19 hinzuzunehmen.

Auf solchen Querschnitten (Fig. 22 und 23) sieht man zunächst unregelmässige Spalten und Lücken, welche Zwischenräumen zwischen den Zellen entsprechen. Die Zellen sind aber nur ganz ausnahmsweise auf allen Seiten von einem Spaltraum umgeben, sodass sie vollständig frei und isoliert liegen. Meistens stossen sie mit einem Teil ihres Umkreises an Nachbarzellen an, ohne dass es möglich wäre, an diesen Stellen die Grenzen zwischen ihnen wahrzunehmen. Man erkennt aber doch soviel, dass die Zellen auf dem Querschnitt, jedenfalls häufig, nicht rund (also nicht einfach spindelförmig) sein können, sondern eine unregelmässig eckige Querschnittsform besitzen müssen.

Der Sehnenquerschnitt erscheint nun ferner wie übersät mit schwarzen Punkten; diese Punkte sind die quergetroffenen Chondrioconten. Die Punkte liegen zum Teil im Innern der Zellen, zum andern Teil aber auf ihrer Oberfläche, welche die eben erwähnten Lücken und Spalten begrenzt.

Auf dieser Oberfläche sind aber ausserdem rote Punkte sichtbar, welche, wenn sie zuerst auftreten, den gleichen oder 
auch einen etwas kleineren Durchmesser haben wie die Chondrioconten; in Fig. 22 sind auf dem ganzen Querschnitt nur erst sehr wenige, in Fig. 23 aber bereits eine grosse Menge davon vorhanden. Diese roten Punkte sind Querschnitte von jungen Bindegewebsfibrillen. Bei einigem Suchen findet man ausser Fibrillenquerschnitten, welche auf der Zelloberfläche gelegen sind, stets solche, welche wie von aussen in das Protoplasma hineingedrückt erscheinen. Mitunter kann man auch einen Bindegewebsfaserquerschnitt beobachten, welcher seine Lage mitten im Protoplasma zu haben scheint; es zeigt sich aber meistens, dass die Stelle, an welcher er liegt, sehr wohl der Grenze zwischen zwei Zellen entsprechen könnte. Noch andere Fibrillenquerscbnitte, besonders dickere, liegen frei in den Spalten und Lücken des Sehnenquerschnitts.

Was nun die Deutung der beschriebenen Bilder anlangt, so bleibt meiner Meinung nach nichts anderes übrig, als anzunehmen, dass die Bindegewebsfibrillen aus Chondrioconten hervorgehen. Die Chondrioconten werden zunächst epicellulär. Sic andern dann ihre chemische Bcschaffenheit, indem sich ihre Substanz in eine solche umwandelt, welche weder durch Eisenhamatoxylin noch durch Fuchsin furbbar ist. Auf diesem Stadium treten diejenigen von ihnen, welche in einer Reihe liegen, untereinander mit ihren Enden in Verbindung. An der Bildung einer Fibrille beteiligen sich zahlreiche Zellen (alle diejenigen, denen ihr Verlauf fest anliegt), indem jede einen Fibrillenabschnitt liefert. Die Fibrillen ündern dann zum zweiten Nal ihre chemische Beschaffenheit, indem sie eine intensive Färbbarkeit für die Collagenfarbstoffe gewinnen. Schliesslich werden sie von den Zellen frei und kommen in den Spalträumen zwischen ihnen zu liegen.

Zugunsten obiger Annahme spricht folgendes. Die jungen Fibrillen treten in ganz derselben epicellulären Lagerung auf, welche die Chondrioconten vorher angenommen haben. Fibrillen, die in die Protoplasmaobertläche eingedrückt erscheinen, haben sich wahrscheinlich im Anschluss an Chondrioconten gebildet, die etwas stecken geblieben sind. Wenn die Chondrioconten nichts mit der Fibrillenbildung zu tun haben, weswegen werden sie dann epicellulär? Und zwar genau zu einem Zeitpunkt, welcher der Fibrillenbildung kurz vorhergeht oder mit der 
Fibrillenbildung zusammenfallt. Die Dicke der jungen Fibrillen ist ferner annahernd die gleiche wie diejenige der Chondrioconten; dass die letzteren vielfach etwas dicker sind, ist wabrscheinlich auf Reagentienwirkung (vergl. oben S. 151) zurückzuführen.

Hierzu kommt noch, dass ein anderes Bildungsmaterial für die Fibrillen auch bei Anwendung anderer Fixierungen und Fürbungen nicht erkennbar ist.

Allerdings ist die Kette der Beweise insofern nicht geschlossen, als in den Figuren die Chondrioconten als getrennte Fadenstücke, die jungen Bindegewebstibrillen dagegen von vornherein kontinuierlich erscheinen. Letztere Tatsache ist meines Erachtens so, wie ich es oben versucht habe, zu erklaren, dass die Chondrioconten ihre Verbindung auf einem Stadium bewerkstelligen, auf welchem sie infolge ihrer veründerten chemischen Beschaffenheit durch die angewandte Methodils nicht darstelluar sind. Diese Annahme hat nichts unwahrscheinliches, wenn man bedenkt, dass der bisherigen Technik auch die unveränderten Chondrioconten verborgen geblieben waren.

Gleich von ihrem ersten Auftreten an zeigen die Binclegewebsfibrillen, wie gesagt, einen wellenförmigen Verlauf (Fig. 1s und 19). I)ieser kann in der Folge sogar noch stärker werden (Fig. 20). Er ist offenbar der Ausdruck davon, dass die Bindegewebsfibrillen von Anfang an ein starkes Längenwachstum entfalten, mit welchem das Längenwachstum der gesamten Sehne zunïchst nicht Schritt zu halten vermag.

Gleichzeitig macht sich eine immer beträchtlicher werdende Dickenzunahme der Fibrillen bemerklich. Diese ist nicht etwa durch Neubildung von den Zellen aus zu erkiaren, sondern beruht auf einem selbstandigen Wachstum der Fibrillen. Zwar treten anfangs noch Nachschübe neuer Fibrillen auf, wovon man sich am besten an Querschnitten überzeugt; man vergleiche Fig. 25, Querschnitt durch die Mittelfusssehne eines 12 tägigen Embryos. Diese werden aber immer spärlicher und baben in Fig. 26 (von einem 14 tägigen Embryo) schon fast gallz aufgehört. Ausserdem verschmelzen die neugebildeten Fibrillen nicht mit den schon vorhandenen, sondern bleiben selbständig.

An den Querschnitten der Fig. 25 und 26 fällt fast noch mehr als früher (Fig. 22-24) die sehr unregelmässige Querschnittsform der Zellen auf, welche mir zu zeigen scheint, dass die be- 
kannte "Flügelform" derselben in der erwachsenen Sehne jedenfalls nicht so ausschliesslicb, wie bisher angenommen wurde, ein Produkt der Fibrillen ist.

Bald nach dem 14. Tag beginnt bei den Sehnen des Mittelfusses eine Septierung aufzutreten; bei einzelnen Sebnen ist sie schon früher vorhanden.

Die Massenvermehrung der collagenen Substanz in den Sehnen des Mittelfusses beruht von jetzt an ausschliesslich auf eigener "formativer Tätigkeit" der Fibrillen. Dementsprechend sieht man nirgends mehr weder Chondrioconten noch junge Fibrillen auf der Zellobertläche liegen; man vgl. Fig. 27, welche einen Teil eines Querschnitts durch eine Mittelfusssehne eines 19 tägigen Hühnerembryos darstellt. Wenn jemand ausschliesslich die Mittelfusssehnen von mehr als 14 tägigen Hühnerembryonen studieren würde, wäre es ilım unmöglich, überhaupt irgendwelche Anzeichen von cellulärer Fibrillenbildung $\mathrm{zu}$ entdecken.

Bemerkenswert ist noch, dass die Zellen, nachdem sie die Produktion von Fibrillen eingestellt haben, eine starke Grössenzunahme erfahren (Fig. 27).

Die gleichen Bilder, welche ich hier für die Fibrillenbildung in der Sehne beschrieben habe, findet man auch im übrigen embryonalen Bindegewebe, abgesehen davon, dass der Verlauf der jungen Fibrillen an den übrigen Stellen ausser in den Aponeurosen und im Periost kein so stark welliger ist.

\section{B. Literatur.}

1. Literatur über Sehnenentwicklung.

Bei der Zusammenstellung der bisherigen Literatur über Sehnenentwicklung habe ich mich auf die neueren Arbeiten (seit 1871) von Rollet, Boll, Lw off, Mall und Merkel beschränt. Auch aus diesen gebe ich nur die tatsächlichen Befunde wieder und übe Kritik nicht überall, wo ich mit den Autoren in Konflikt komme, sondern nur stellenweise, wo es mir nötig erscheint.

Nach Rollet (1871, S. 65 u. 66) sieht man bei den Sehnen junger Embryonen anfangs dicht gedrängt liegende rundliche Bildungszellen. Diese Zellen verlängern sich darauf in der Richtung der Längenachse der Sehne und ebenso strecken sich ibre Kerne. Die in die Länge gewachsenen Zellen 
scheinen aus einer stärker lichtbrechenden Substanz gebildet als die ursprünglichen Zellen und sind leichter zu isolieren. Eine helle, glatte Zwischensubstanz, wie sie bei der Bildung des Bindegewebes im Netze der Fibrillenanlage vorausgeht, ist hier niemals $z u$ sehen. Es treten vielmehr sehr frühe anfangs spärlich, später zwischen den immer mehr verlängerten und besser begrenzten und verschmächtigten Zellen immer zahlreicher die feinen, glatten, völlig homogenen und durchsichtigen Fibrillen auf. Solche lassen sich durch Zerzupfen schon isolieren, wenn die Zellen noch verhältnismässig wenig gestreckt sind und sind häufig über die ganze Länge des herausgeschnittenen kleinen Sehnenstückchens hin in continuo $\mathrm{zu}$ verfolgen. Sind die Zellen länger geworden - und sie verlängern sich absolut sowohl als relativ zu ihrer Breite, während die letztere absolut kleiner wird - dann hat auch die Zahl der Fibrillen schon bedeutend zugenommen. Diese sind wieder über die ganze Sehne hin ununterbrochen zu verfolgen, also über eine ganze Reihe von Zellen hinlaufend. Endlich sind zwischen einer grösseren Anzahl der neugebildeten Fibrillen schmächtigere, an ibren Enden lang und fein ausgezogene Spindeln enthalten, dieselben lassen sich leicht isolieren, ihre feinen Enden schmiegen sich ebenfalls innig an die Fibrillen an. Es gelingt aber auch hier bei gehöriger Ausdauer, sich von der Unabhängigkeit beider zu überzeugen und zahlreiche Fibrillen vollstïndig glatt, homogen und ohne die Andeutung irgend eines Knotens von dem einen Ende der Sehne bis zum andern zu verfolgen. Das letzte ist, wie gesagt, schon möglich, wenn die Zellen noch verhältnismässig breit und kurz sind. Unter mächtiger Zunahme der Fibrillen und Auseinanderrücken der Zellen, die sich mehr und mehr verschmächtigen, geht die Entwicklung weiter.

Boll (1872), welcher ebenso wie Rollet, wenn anch in anderer Weise als dieser, für die celluläre Entstehung der Bindegewebsfibrillen eintritt, findet. dass die genetischen Beziehungen der Zellen zu den Fibrillen allerdings speziell bei der Sehne schwierig nachzuweisen seien.

Nach B oll präsentiert sich eine in toto unter das Mikroskop gebrachte Sehne aus der unteren Extremität eines Hühnerembryo als ein regelmässiger Strang feinfibrillären, lockigen Bindegewebes, in welchen ovale Kerne eingebettet sind. Um die Kerne ist nur selten eine Andeutung des Protoplasma in Gestalt einer körnigen Anhäufung nachzuweisen: in der Mehrzahl der Fälle erscheinen sie einfach nackt. Wenn man jedoch abgeplattete Sehnen auswählt und sie bei stärkerer Vergrösserung untersucht, gelingt es nach Boll festzustellen, dass die Zellen an ihren beiden Enden, der Achse der Sehne parallel, sich ausfasern und durch die Fibrillen mit den anstossenden Zellen zusammenhängen.

Die ron verschiedenen Zellen gebildeten Fibrillenabschnitte verschmelzen zu einer einzigen Fibrille. Jedenfalls vermag sich Boll nur unter dieser Annahme das folgende Faktum zu erklären: zerzupft man eine Sehne aus einem etwas weiter vorgeschrittenen Entwicklungsstadium parallel der Längsachse, so erhält man nicht selten Fibrillenbündel, welche von einer Reihe von Zellen bedeckt werden, ohne dass sich auf dieser Strecke eine einzige freie Endigung einer Fibrille nachweisen liesse. 
An solchen Zupfpräparaten sieht man ferner die mit dem Fibrillenbïndel noch in genetischem Zusammenhang stehenden Zellen diesem einseitig aufliegen. Boll glanbt daher annehmen zu müssen, „dass von seiten der Zellen der Sehne die Bildung der Fibrillen wesentlich nach einer Seite und nach einer Richtung hin erfolgt ist (man vergleiche hierzu die Kritik von I w off).

Nach Boll soll anfangs (bis zum 14. Tage) eine vollständige Kontinuität zwischen dem Fibrillenbündel und den aufliegenden Zellen bestehen : , es gelingt nicht durch irgendwelche mechanische oder chemische Behandlungsmethode die Zellen von dem Fibrillenbündel abzulösen. Ein Versuch, die Zellen zu isolieren, wird jedesmal auch das ganze Fibrillenbündel zerstören. Wenige Tage später, gewöhnlich nicht vor dem Anfang des 18. Tages (mitunter auch schon mit dem 16. Tage), gelingt es jedoch, die Zellen von der Oberfläche der Fibrillenbündel, mit denen die Zellsubstanz nun nicht mehr in genetischem Znsammenhang steht, abzuheben; es stellen dieselben jetzt flache, unregelmässig rechteckige und rhomboidische Zellen dar, die der Oberfläche der Fibrillenbündel aufliegen."

Lw off (1890, S. 204) konnte in der Sehne eines $5 \mathrm{~cm}$ langen Schafembryo dicht aneinanderliegende Zellen mit ovalen Kernen unterscheiden. Ausserdem lässt sich in der Masse eine langliche Streifung bemerken. Wenn man das Prïparat etwas zerzupft, so kann man sehen, woher diese Streifung rührt. Die an beiden Enden in lange, sehr feine Auslaufer ausgezogenen Zellen sind in länglichen Reihen gelagert; diese sind allseitig mit feinen, parallellaufenden Fibrillen umhüllt. Lwoff kann daher mit Boll nicht übereinstimmen, wenn dieser sagt, dass in der Sehne die Zellen nicht in der Nitte des Fïbrillenbündels, sondern auf deren Oberfläche sich befinden.

Im Lauf der weiteren Entwicklung scheinen die Fibrillen in jedem Bündel sich nach $L$ w off dichter und inniger aneinander zu legen. Bei einem $16 \mathrm{~cm}$ langen Schafembryo konnte er schon dichte Bündel sehen, die nur noch eine feine (auf ihre Zusammensetzung aus fest aneinander liegenden Fibrillen hinweisende) Längsstreifung zeigten. Gleichzeitig werden die Zellkörper mehr und mehr verschmächtigt; erst bei ausdauerndem Zupfen gelingt es, die dünnen spindelförmigen Zellen zu isolieren; $\mathrm{L}$ w off glaubt, dass die Bindegewebskörperchen der erwachsenen Sehne auch nichts anderes sind, als die Reste der Bildungszellen, die in den Bündeln geblieben sind.

Dass Hand in Hand mit der Fibrillenzunahme eine "Verschmächtigung" der Zellen einhergeht, wie ausser $\mathrm{L}$ woff auch 
Rollet angibt, muss ich entschieden in Abrede stellen; ich finde im Gegenteil, dass die Zellen und ihre Kerne vom Beginne der Fibrillenbildung an erst langsam, später rasch grösser werden.

Mall (1891, S. 325) beschränkt sich auf eine kurze und nicht zutreffende Bemerkung: „Die Fasern einer kleinen in der Entwicklung begriffenen Sehne findet man niemals in der Verbindung mit Zellen, aber sie nehmen an Zahl zu und werden länger".

Merkel (1895, S. 43) findet in der Sehne die entstehenden Fasern der Obertläche der Bildungszellen dicht anliegen; „man versteht", sagt er, „bei ihrer Betrachtung sehr wohl die Beschreibungen, nach denen die Bindegewebsfibrillen direkte Abkömmlinge der Zellen sind". Jedoch vermochte er keine Tatsachen ausfindig $\mathrm{zu}$ machen, welche eine direkte Umwandlung des Zellprotoplasmas in fibrilläre leimgebende Substanz als einzige Deutung zulassen. Vielmehr muss er annehmen, dass durch die Tätigkeit der Zellen eine Substanz ausgeschieden wird, welche dann fibrillar zerfällt.

Während es Merkel aber damals nicht gelingen wollte, eine derartige Substanz nachzuweisen, ist ihm dies, wie er sagt, neuerdings (1909, S. 374) mit Hilfe der heute zur Verfügung stehenden Methoden geglückt. Auch diese lassen in den ersten Stadien das Zellprotoplasma noch so hell erscheinen, dass sein Nachweis grosse Aufmerksamkeit erfordert. "In den Zwischenräumen zwischen den Zellen aber findet man eine mit Mallory sich blau färbende Substanz, welche bei ihrem Erscheinen eine Struktur nicht erkennen lässt. $\mathrm{Zu}$ ibrem Nachweis wurden die distalen Teile der Extremitäten und des Schwanzes von $30 \mathrm{~mm}$ langen Schweinsembryonen benutzt. Im Anfang umgibt sie die Zellen in einer zusammenhängenden Masse; diese sind in sie gleichsam eingegossen." Sehr bald aber bäuft sich die in Rede stehende Substanz hier in etwas grösserer, dort in etwas geringerer Menge an und formiert sich schliesslich zu Fasern von rundlichem Querschnitte.

Hierzu möchte ich schon an dieser Stelle bemerken, dass ich die Malloryfärbung ebenfalls an Material, welches teils in Flemmingschem, teils in Zenkerschem Gemisch fixiert war, in Anwendung gebracht habe, dass ich aber von einer formlosen Substanz, welche den Bindegewebsfasern Entstehung gibt, nichts 
habe walırnehmen können. Der Vorwurf, welchen Merkel (1909, S. 371) gegenuber Lw off erhebt, dass seine Beobachtungen zu einer Zeit eingesetzt hätten, in welcher die Fibrillenbildung bereits beendet sei, trifft mir gegenüber jedenfalls nicht zu.

\section{Literatur über Entstehung der Bindegewebs- fibrillen im allgemeinen.}

a) Aus der älteren Literatur von Schwann bis Flemming.

Der Streit über die Herkunft der collagenen Fibrillen bezog sich bekanntlich lange Zeit hindurch auf die Frage, ob sie sich aus dem Protoplasma der Bindegewebszellen oder ohne Beteiligung der letzteren in der Intercellularsubstanz bilden.

Der erste Autor, welcher sich überhaupt mit der Frage beschäftigt hat, $T h$. Schwann (1839), liess die collagenen Fibrillenbündel sowie auch die elastischen Fasern durch Auswachsen und Umwandlung embryonaler Zellenleiber entstehen.

Ebenfalls für die celluläre Entstehung trat M. Schultze ein, dessen Ansicht, wie sie uns durch seinen Schüler Boll (1872, S.36) übermittelt wurde, dahin ging, dass das Protoplasma der Embryonalzellen die Fibrillen auf seiner Oberfläche und aus seiner Substanz vermöge seiner formativen Tätigkeit bildet. „Ebensowenig der Natur entsprechend, wie wenn wir sagen wollten: Protoplasma wandle sich in Cellulose, in Stärke, in Fett usw. um, kann von einer direkten und unmittelbaren Umwandlung des Protoplasma in Fibrillensubstanz die Rede sein. Vielmehr ist auch die Fibrillensubstanz ebensowohl wie jene eben genannten Substanzen Cellulose, Fett, Stärke, etwas Neues, durch die formative Tätigkeit des Protoplasma Gebildetes."

Boll (1872) neigt selbst dieser Grundanschauung seines Lehrers ebenfalls zu, kommt aber bei einem Versuch, sie durch Beobachtung zu erweisen, im wesentlichen auf die Schw an nche Ansicht zurück, nach welcher Zellenausläufer zu Fibrillen auswachsen oder sich in Fibrillen auffasern.

Eine Schilderung, die mehr der Voraussetzung von M. Schultze entspricht, gab Rollet (1871 und 1872). 1871 (S. 61 u. folg.) untersuchte er die Entwicklung des Netzes und der Sehnen und gelangte dabei zu dem Resultat, dass mit Beginn der Fibrillenbildung eine „grössere Menge von homogener Sub- 
stanz" auftritt, auf deren Kosten die Fibrillen durch eine Art Prägung entstehen; diese homogene Substanz betrachtet er nicht als Intercellularsubstanz, sondern lässt sie aus einer Metamorphose des Protoplasmas hervorgehen.

Später sprach sich Rollet noch bestimmter zugunsten der Ansicht aus, dass die Bindegewebsfibrillen der Zelisubstanz ihre Entstehung verdanken. Wir sehen, heisst es bei ihm (1872, S. 264), in der Nabelschnur und in der Sehne "Fibrillen sich bilden in den äusseren Teilen der Bildungszellen". „Eine Umbildung schreitet successive von aussen nach innen vor, welche unmittelbar mit der Fibrillenbildung einhergeht. Wie viele Eigenschaften des ursprünglichen Protoplasma jene Teile der Zellen noch an sich tragen, welche die Fibrillen bilden, und wie sie allmählich übergehen in das um den Kern gelagerte nicht veranderte Protoplasma, das sind Fragen, für deren Entscheidung uns bis jetzt noch wenig Mittel zur Verfügung stehen." - Auch im grossen Netz müssen die Bedingungen für die Entstehung der Fibrillen in gleicher Weise wie in der Nabelschnur und in der Sehne realisiert sein.

Die gleiche Meinung vertritt auch Rollets Schiiler, L w off (1890), welcher die Bindegewebsfibrillen „auf der Oberfläche der Bildungszellen aus dem Zellprotoplasma" durch eine "Differenzierung der Oberflächenschichte" entstehen lässt.

Eine neue und wichtige Wendung nahm die Lehre von der cellularen Entstehung der Bindegewebsfibrillen 1891 durch eine Arbeit von Flemming, welcher ebenso wie Rollet und $L$ w of $f$ die Schwannsche Lehre verwirft, die Bildung der Fasern aber nicht wie diese auf der Oberfläche des Zelleibs, sondern in den peripheren Schichten desselben vor sich gehen lässt; und zwar ist es ihm am wabrscheinlichsten, dass die Fäserchen „aus der Faserstruktur der Zellsubstanz selbst entstehen, indem diese sich teilweise zu parallelen Fibrillen streckt und sich dabei umformt" (1891, S. 221).

Die Ansicht, dass die Bindegewebsfasern in der Intercellularsubstanz ohne Beteiligung der Zellen entstehen, war lange Zeit die allein herrschende. Sie wurde zuerst von Henle (1841) vertreten, welcher die Fibrillen in einer Intercellular- oder "Grund"substanz auftreten liess, welche, der 
damaligen Anschauung entsprechend, von vornherein zwischen den Zellen vorhanden sein sollte. Nachdem jedoch die Intercellularsubstanz durch M. Schultze und L. Beale ihrerseits als celluläres Produkt erkannt war, musste wenigstens eine indirekte Teilnahme der Zellen an der Entwicklung der Fibrillen zugegeben werden; man vergleiche Ranvier (1875, S.410). Die neueren Vertreter einer "freien" Fibrillenbildung aber fassen die Intercellularsubstanz entweder direkt als metamorphosiertes Protoplasma auf oder nehmen an, dass die Zellen eine von der Intercellularsubstanz verschiedene formlose Substanz produzieren, in welcher sich secundar Fibrillen differenzieren.

Man muss demnach sagen, dass von der alten Lehre der extracellulüren Entstehung heute nur noch herzlich wenig oder fast gar nichts mehr übrig ist. Aber auch die Meinung, dass die Fibrillen durch Umwandlung von Protoplasmafortsätzen entstehen, ist in der letzten Zeit nur noch selten (von $Z$ achariad ès und v. Szily) vertreten worden.

Die Frage, die seit 1891 im Vordergrund steht, ist vielmebr diese: Sind die Bindegewebsfibrillen Umbildungen einer cytoplasmatischen Struktur, wie Flemming und mit ihm Reinke, Waldeyer, Spuler, Studnička, Hansen, Spalteholz und andere annehmen? Oder bilden sie sich, wie die Mehrzahl speziell der neueren Autoren, Merkel, v. Ebner, Mall, Retterer, Renaut, Laguesse, Bruni, glauben, secundär aus ungeformter Substanz? Sei es nun, dass diese, wie schon Rollet und Lwoff meinten, durch Differenzierung einer Oberflächenschicht der Bindegewebszellen entsteht oder dass sie von den Zellen nach Art eines Sekrets oder einer "Cuticularbildung" abgeschieden wird:

b) Neuere Literatur von Flemming bis heute.

a) Die Bindegewebsfibrillen entstehen durch Umwandlung von Protoplasmafortsützen (Zachariadès, v. Szily).

Zachariadès (1898, 1, S. 490 und 491) fand in dem gallertartigen Bindegewebe, das beim Frosch in der Kniegegend unter der Aponeurose des m. triceps femoris gelegen ist, grosse Zellen mit stark körnigem Protoplasma, von denen sehr zahl- 
reiche Fortsätze ausgehen. Diese Fortsătze teilen sich wiederholt und anastomosieren entweder miteinander oder mit den Fortsätzen benachbarter Zellen. In einer bestimmten Entfernung von der Zelle ordnen sie sich und nehmen einen geradlinigen Verlauf all; gleichzeitig ändern sie ihr Lichtbrechungsvermögen; sie fărben sich anfangs noch stellenweise, in weiterer Entfernung von der Zelle aber nirgends mehr. Auf diese Weise wandeln sie sich in Fibrillen um, welche sich aneinander legen, um. Bündel zu bilden; jedoch können sie auch zunächst vollkommen isoliert bleiben und erst nach sehr langem Verlauf ein entferntes Bündel verstärken.

Z a chariadès halt es für wahrscheinlich, dass dieser Entwicklungsmodus derjenige der Bindegewebsfibrillen im allgemeinen sei. Daron kann nun aber nach meinen Beobachtungen keine Rede sein; ich finde vielmehr wie eine grosse Anzahl anderer Autoren, dass die Fibrillen sich auf der Oberfläche der Zellen und der Zellauslaufer bilden.

Zu obigem macht $Z$ achariades $(1898,2$, S. 214) noch folgenden Zusatz: Man sieht mitunter Zellfortsätze, die, an einer oder mehreren Stellen hintereinander, spindelförmig verdickt sind und solche, die keulenförmig endigen. Diese Verdickungen färben sich wie Protoplasma und zeigen zuweilen eine Art Kern. Z achariad ès versucht diesen Befund zu deuten, indem er sich vorstellt, dass die Fortsätze der Bindegewebszellen, um Fibrillen von beliebiger Länge bilden zu können, imstande seien, Protoplasmabruchstücke anderer ähnlicher Zellen in sich aufzunehmen, denen sie auf ihrem Wege begegnen.

An derselben Stelle (1898, 2, S. 214 u. 215) beschreibt $\mathrm{Z}$ a ch a ria dè s noch einen etwas anderen Modus der Fibrillenbildung, welchen er an den Zellen des gallertigen Bindegewebes unter dem Sesambein der Achillessehne des Frosches beobachtet hat. Diese Zellen sind länger als breit, ihre Längsachse liegt der Richtung der Fibrillen, denen sie Entstehung geben, parallel. Sie besitzen zweierlei Arten von Fortsätzen: die einen, lateralen, sind membranförmig und teilen sich wiederholt; die anderen, longitudinalen sind fadenförmig und von ausserordentlicher Länge; sie gehen entweder vom Zellkörper oder von den seitlichen Fortsätzen und zwar von longitudinal verlaufenden Leisten ab. Man beobachtet nun nach $\mathrm{Z} \mathrm{a} \mathrm{ch} \mathrm{a} \mathrm{ri} \mathrm{a} \mathrm{dè} \mathrm{s}$, dass die Leisten mit den von ihnen entspringenden longitudinalen Fortsätzen sich von den Zellkörpern und ihren seitlichen Fortsätzen loslösen; es hat durchaus den Anschein, dass sie sich in Fibrillen umwandeln.

v. Szily (1908) beschreibt, dass "die faserigen Elemente des embryonalen Bindegewebes, die sogenannte fibrilläre Zwischensubstanz des Mesenchyms, nicht von den Zellen selbst gebildet, 
sondern schon an Ort und Stelle vorgefunden" werden; wobei er unter „embryonalem Bindegewebe“ das Zellsyncytium des Mesenchyms und unter den „faserigen Elementen “ oder der „fibrillaren Zwischensubstanz" desselben die Zellausläufer versteht, durclı welche die Mesenchymzellen wenigstens teilweise zusammenhängen. Überall dort, wo in frühen Stadien die epithelialen Zellschichten der embryonalen Organanlagen durch kleinere oder grössere Zwischenrăume voneinander getrennt sind, kommt es nach v. Szily zunächst zur Ausbildung feiner Intercellularbrücken bezw. von anastomosierenden Protoplasmafortsatzen. "Ist der Spaltraum eng, so stellen diese Verbindungen nichts anderes dar als protoplasmatische Zusammenhänge der gegenüberliegenden Zellen. In dem Maße, als sich der Spaltraum verbreitert, verlängern sich diese Fortsätze, bekommen zahlreiche Seitenäste und bilden auf diese Art ein Fasergerüst" (S. 727). Dieser Zustand des „zellfreien faserigen Stützgewebes "verändert sich nun überall auf die gleiche typische Art durch das Auftreten von Mesenchymzellen, welche in das Fasergerüst hineinwandern und mit den Fasern in innige Verbindung treten. "Aus dieser Verbindung entsteht das embryonale Bindegewebe mit seinen beiden Komponenten: Mesenchymzelle und fibrilläre Zwischensubstanz. Die neu hinzutretenden Zellen sorgen für die Ernährung und das Wachstum der sich von ihrem Nutterboden Ioslösender Fasern" (S. 742).

Ich selbst habe im vorigen Jahre (1908, S. 837) bei einem Hühnerembryo von ca. 21/2 Tagen zwischen Cutisblatt und Epidermis ein von Zellfortsätzen gebildetes zierliches Gerüstwerk, wie es v. Szily schildert, ohne Kenntnis seiner im selben Jahr erschienenen Arbeit beschrieben und in Fig. 31 abgebildet. Ich stimme v. Szily darin bei, dass ähnliche Gerüstwerke im embryonalen Körper verbreitet sind, und habe auch an der genannten Körperstelle selbst beobachtet, dass in das Gerüstwerk später Mesenchymzellen einwandern. Dass aber die Gerüstbalken sich alsdann von ihrem Mutterboden loslösen und sich mit den eingewanderten Mesenchymzellen verbinden, betrachte ich nicht, wie v. Szily, als "über allem Zweifel erbaben", sondern als irrtümlich. Ich nehme meinerseits an, dass dieses protoplasmatische Gerüstwerk in den meisten Fälen hinterher rückgebildet wird und dass sich an seiner Stelle das „Zellsyncytium des. 
Mesenchyms" etabliert, welches von den eingewanderten Zellen seinen Ausgang nimmt. Wenn die Anschauung v. Szilys richtig wäre, dass das Syncytium durch eine "Vermischung von Zellen und Fasern" entsteht, so müsste dem Auftreten desselben an allen Stellen die Bildung eines derartigen Gerüstwerks vorausgehen, was aber keineswegs der Fall ist, z. B. nicht in den Extremitäten.

Ein derartiges Netzwerk, wie das von v. Szily und mir beschriebene, mag man mit einem gewissen Recht, wie es v. Szily tut, als "zellfreies embryonales Stützgewebe" bezeichnen können. Jedoch sollte man auf alle Fulle vermeiden, dieses „Stützgewebe" als "fibrillär" und die Balken desselben als Fibrillen anzusprechen; ebenso wie man die Auslaufer der Mesenchymzellen nicht als Fasern schlechthin oder gar als „fibrilläre Zwischensubstan\%" bezeichnen sollte. Denn mit Bindegewebsfibrillen haben diese Protoplasmafortsätze nicht das geringste $\mathrm{zu}$ tun ${ }^{1}$ ). v. Szily allerdings scheint dies zu glauben; denn er "skizziert" in seiner Arbeit kurz "die Entwicklung unserer Kenntnisse von der Histiogenese des collagenen Bindegewebes", damit seine Befunde "in den Rahmen dieser Forschungen eingefügt werden" könnten (S.706); ferner schreibt er z.B.S.729, dass, nachdem innerhalb des Syncytiums die ersten Anlagen der Blutgefässe und der Gruppe der Stützsubstanzen sich ausgebildet häten, „das Vermögen, kollagene Fasern zu bilden“; , an die sich nicht in spezieller Richtung (Knorpel, Knochen etc.) umwandelnden Zellen des postembryonalen Bindegewebes überginge".

(3) Die Bindegewebsfibrillen sind Umbildungen einer cytoplasmatischen Struktur (Flemming, Reinke, Wald eyer, Spuler, Studnička, Hansen, Spalteholz u.a.).

Meine eigene Ansicht von der Entstehung der Bindegewebsfasern steht derjenigen Flemmings am nächsten; jedoch vermag ich ihm bezüglich der Deutung, welche er seinen Befunden gibt, nicht beizustimmen.

Flemming (1891) beobachtete an jungen Bindegewebszellen aus dem parietalen Bauchfell der Salamanderlarve und an

1) Jedoch enthalten sie, wie ich 1908 S. 837 beschrieben habe, Chondrioconten, welche sich vielleicht ihrerseits, wenigstens stellenweise, in Bindegewebsfibrillen umbilden könnten. 
ihren Fortsätzen eine feine Streifung, „die ohne $Z$ weifel der Anlage von collagenen Fibrillen entspricht". An rubenden Zellen kann man noch darüber zweifelhaft sein, ob diese Streifung in den Zelleibern oder eben noch daneben liegt. Dagegen wird nach Flemming jeder Zweifel beseitigt, wenn man sich teilende Zellen untersucht, bei denen eine Verdickung des Zellkörpers und eine eigentümliche Veränderung desselben eintritt, welche die in ilm enthaltenen Strukturen stärker sichtbar macht. Betrachtet man nun solche Zellen des Bindegewebes, am besten recht grosse, wie sie sich $z$. B. im Bauchfell oder der Lunge jüngerer Larven von etwa $3 \mathrm{~cm}$ Länge finden, so sieht man in der Zellsubstanz nicht bloss die Fäden der Polstrahlung und die mit ihnen in Zusammenhang stehenden, netzig erscheinenden Fadenwerke in scharfer Färbung hervorgehoben, sondern daneben zahlreiche Fasern, ebenso tingiert, von bald geradem, bald welligem Verlauf, in der Längsrichtung der Zelle und ihrer Ausläufer angeordnet. Diese Fasern, die „gerade so aussehen wie die der gesamten collagenen Faserung des Gewebes" (S. 221), sind sicher noch im Zellkörper gelegen; denn sie erscheinen bei derselben Einstellung, bei der man auch die Fasern der Polstrahlung sieht.

Flemming möchte nun aber - offenbar wegen der Bilder, welche die Zellen im Ruhezustand bieten - keineswegs annehmen, dass die Fibrillen sich überall im ganzen Zellkörper bilden; es erscheint dies vielmehr nach ihm nur im peripheren Teil (am Bauchfell nur einseitig) zu geschehen; jedenfalls aber fällt die Anlage der Fasern noch in den Bereich des Zellenleibes.

Was die Art und Weise anlangt, wie die Fasern sich bilden, so lässt F le m ming in seiner ersten Arbeit (1891) unentschieden, ob sie, „woran man wohl zunächst denken wird, aus der Faserstruktur selbst entstehen, indem diese sich teilweise zu parallelen Fibrillen streckt und sich dabei chemisch umformt, oder indem die letzteren, an diesen sich streckenden Fadenwerken entlang, aus der Interfilarmasse geprägt werden, was ja immerhin auch möglich bleibt“. In einer späteren Arbeit dagegen aus dem Jahre 1897 kommt er auf die letztere Möglichkeit nicht wieder zurück, sondern nimmt an, dass die Fibrillen sich durch eine "Umprägung der Fadenstruktur" des Protoplasmas bilden.

$\mathrm{Zu}$ dieser Darstellung Flemmings habe ich folgendes $\mathrm{zu}$ bemerken. Die von Flemming beschriebenen intracellulären 
Fibrillen werden von jhm selbst als Bindegewebsfasern bezeichnet. Nun erlauben aber die von ihm bei seinen Arbeiten angewandten Färbungsmethoden nicht, junge Bindegewebsfibrillen einerseits und cytoplasmatische Fila oder Chondrioconten andererseits scharf zu unterscheiden. Ich bin nun meinerseits der Ansicht, dass die intracellulären Fibrillen Flemmings nicht Bindegewebsfasern, sondern Chondrioconten sind. Bindegewebsfasern können es deshalb nicht sein, weil solche niemals (auch nicht während der Mitose) im Innern, sondern stets auf der Oberfläche oder in der oberflächlichsten Schicht der Zellen gelegen sind. Andererseits habe ich mich an Schnitten durch den Schwanz der Salamanderlarve davon überzeugt, dass in den Bindegewebszellen dieses Tieres tatsächlich lange dünne Chondrioconten vorhanden sind.

Diese Fibrillen (Chondriconten) treten auch nicht erst, wie Flemming annimmt, in den Bindegewebszellen auf, entstehen nicht erst in ihnen durch eine "Umprägung" aus der Filarmasse, sondern sie sind die Filarmasse selbst, welche von vornherein in den Zellen vorhanden ist. Dass es sich um rein protoplasmatische Fila handeln könnte, wurde von Flemming deshalb nicht in Betracht gezogen, weil er die irrtümliche Vorstellung hatte, dass die Filarmasse sich als ein feineres Fadenwerk noch daneben fünde.

Aus dem eben Gesagten erklürt sich folgende weitere Differenz, welche ich mit Flemming habe. Ich lasse die Bildung der Bindegewebsfasern nicht, wie dieser, „im Bereich des Zelleibes“, sondern im allgemeinen auf der Zellobertlache vor sich gehen. Mit Flemming stimme ich jedoch darin überein, dass ich sie von den Fila des Cytoplasmas ableite. Dies war allerdings sowohl bei Flemming als auch bei denjenigen Autoren, welche sich ihm angeschlossen haben, nur eine Annahme, wăhrend ich für mich. in Anspruch nehmen möchte, Beobachtungen beigebracht zu haben, welche die Genese der Bindegewebsfibrillen aus Chondrioconten, wenn nicht beweisen, so doch jedenfalls im hohen Grade wahrscheinlich machen,

Reinke (1894), welcher die Befunde Flemmings über die Bildung collagener Fasern am Bauchfell der Salamanderlarve bestätigt hat, findet in den sich teilenden Zellen um die Teilungsfigur herum färbbare Körnchen; in den ruhenden Zellen sind sie nur bei sehr starker Färbung sichtbar. Reinke vermutet, dass 
diese Körnchen das Material zum Aufbau der Fibrillen abgeberr könnten. Flemming hat in seiner zweiten Arbeit (s. unten) gleichfalls das Vorhandensein dieser Körnchen in sich teilenden Bindegewebszellen konstatiert, steht aber der Ansicht, nach welcher sie das Material zur Bildung der Fibrillen abgeben, skeptisch gegenüber; er hălt es vor der Hand für ganz möglich, dass diese Körnermassen aus dem Kern stammen. Be n da $(1899,1)$ hat dann die Vermutung ausgesprochen, dass die Reinkeschen KörnerVitochondrien sein könnten. Ich selbst habe früher (1907, 2, S. 403 bis 404) ebenfalls daran gedacht, bin aber von dieser Meinung zurückgekommen, seitdem ich gefunden habe, dass die Bindegewebszellen der Salamanderlarve überhaupt keine Mitochondrien, sondern ausschliesslich Faden, Chondrioconten, enthalten.

Waldeyer (1895, S. 75T) bat beim Igel durch Anwendung des Ranvierschen Verfahrens (sucubtane Injektion von Farblösungen) Bilder gewonnen, die ihn veranlassen, sich in Bezug auf die vorliegende Frage auf die Seite Flemmings zu stellen.

Spuler (1896) fand bei einem Schafembryo in den Zellen der Nabelschnur eine körnige Masse, von welcher Fïden ausgehen, welche ihrerseits mit Bindegewebsfibrillen in Zusammenhang stehen. Ähnliche Bilder sah er auch im Amnion von Schafembryonen und im Nabelstrang und den Bauchdecken eines viermonatlichen menschlichen Embryo. Er kann seine Beobachtungen nur so deuten, „dass die Fibrillen im Protoplasma der Zellen gebildet und dann frei werden, indem sich dieses von ihnen zurïckzieht". - Ich konstatiere demgegenüber, dass ich einen Zusammenhang zwischen Zellfaden und Bindegewebsfibrillen in dem von Sp uler gemeinten Sinn, dass ein Zellfaden sich kontinuierlich in eine Bindegewebsfibrille fortsetzt, niemals beobachtet habe. Auch nehme ich nicht an, dass das Protoplasma sich von den Zellfäden zurückzieht, sondern lasse diese an die Zelloberfläche verlagert werden.

In einer Arbeit aus dem Jahre 1897 hat Flemming die Beschreibung der fibrillenbildenden Zellen des Salamanderbauchfells nach neuen Präparaten noch etwas spezieller gegeben. Sodann hat er, um die Ansicht Merkels zu widerlegen, welcher 1895 für eine intercellulåre Bildung der Bindegewebsfasern nach Untersuchungen hauptsächlich an der Nabelschnur eintrat, dieses 
Gewebe gleichfalls kontrolliert, daneben aber auch das "Gallertgewebe" in den Kiemenblättern und der Schwanztlosse von Salamanderlarven herangezogen. Bei dem letztgenannten Objekt sowohl wie in der Nabelschnur findet Flemming die Fibrillen zur Zeit, wo sie sich bilden, stets in oder dicht an den Zellkörpern und ibren Ausläufern gelagert; es scheint ihm daher auch hier kein Grund für die Annahme vorzuliegen, dass die leimgebenden Fasern intercellulär entstehen.

Ich selbst bin durch eigene Untersuchung des Gallertgewebes bei der Salamanderlarve zu dem Resultat gekommen, dass die Fibrillen, welche Fle mming in den Zellen und ihren Ausläufern gesehen hat, keine Bindegewebsfasern, sondern (ebenso wie in den Zellen des Bauchfells) Protoplasmafaden oder Chondrioconten, immerhin also in Anbetracht dessen, dass es sich um Bindegewebszellen handelt, "Anlagen" von Bindegewebsfasern sind.

Anders liegt die Sache hinsichtlici der Fibrillen der Nabelschnurzellen.

Bei letzterem Objekt hat Golowinski (1907) die Befunde Flemmings sowie die Deutung, welche er ihnen gegeben hat, in allen wesentlichen Punkten bestätigt. Er beschreibt (S. 212-213) "fibrillenartige Gebilde“, welche, stets dicht auf der Zelle liegend, von einer Zelle auf die andere, von einem Ausläufer auf den anderen, kontinuierlich über mehrere Zellen ziehen. „An Querschnitten sieht man, dass die Bindegewebszellen von einer ganz feinen und dünnen Grenzschichte überzogen sind, welche im Querschnitt als schmaler, dunkler Ring hervortritt, und auf dieser Grenzschichte liegen die Durchschnitte der Fasern, welche als regelmässige runde dunkle Punkte erscheinen, deren Fasernatur durch Drehen der Mikrometerschraube unschwer zu erweisen ist." Die epicelluläre Lagerung betont Golowinski besonders gegenüber Flemming, nach welchem die Fasern nicht nur „an“, sondern auch „in den Zellen und ibren Ausläufern" liegen. Golowinski lässt aber ebenso wie Flemming die in Rede stehenden Fibrillen von den Zellen frei werden und sich in collagene Fasern umwandeln. Er macht ferner (S. 217) folgende Angaben über die Entstehung der von ihm sogenannten „präcollagenen“ Fasern: „Bevor die präcollagenen Fasern sichtbar werden, sind die Zellen mit zahlreichen, unzweifelhaft epicellulär liegenden Körnchen bedeckt, welche in Eisenhämatoxylin dieselbe Farbe annehmen wie die 
präcollagenen Fasern selbst. Diese Körnchen sind zuerst unregelmässig auf der Oberfläche der Zellen verstreut, in der Folge aber stellen sie sich, vermutlich unter dem Einfluss der Zellen selbst, reihenweise ein, wobei sie wie die präcollagenen Fibrillen von einer Zelle auf die andere übergehen. Diese Körnchenreihen fliessen endlich $\mathrm{zu}$ den präcollagenen Fasern zusammen."

Ich habe $(1907,1)$ zu diesem letzteren Punkt vermutungsweise geäussert, dass die epicellulären Körnchen von Golowinski Mitochondrien sein könnten, „die demnach ursprünglich im Innern der Zellsubstanz gelegen wăren". "Ich selbst habe", fuhr ich damals fort, „einstweilen auf Grund eigner Untersuchung des Nabelschnurbindegewebes konstatieren können, dass die präcollagenen Fasern von Golowinski die gleichen Färbungsreaktionen wie Chondrioconten geben"; ich meinte daher annehmen zu dürfen, dass sie mit solchen identisch seien.

Merkel (1909, S. 361), unter dessen Augen die Arbeit Golowinskis entstand, kann seine Angaben vollinbaltlich bestätigen, mit Ausnahme derjenigen, nach welcher die epicellulïren Fasern sich in collagene Fasern umwandeln. An der Richtigkeit dieser Behauptung wurde er bei einer nochmaligen Durchsicht der von Golowinski zurückgelassenen Priparate zweifelhaft, weil Fasern, welche sich von der Zelle ablösen und frei werden (wie die von Golowinski in Fig. 2 gezeichnete), zu den grössten Seltenheiten gehören. Merkel muss seinerseits erklären, dass die fraglichen faserartigen Gebilde mit der Entstehung der collagenen Fasern nichts zu tun haben, ist vielmehr der Meinung, dass sie „der inneren Protoplasmastruktur angehören". „Es kommen einerseits Fibrillenbildungen, welche ihnen durchaus gleichen, in Zellen vor, die zur Bildung collagener Fasern nicht befähigt sind, wie z. B. in den glatten Muskelfasern des Darms von Salamanderlarven und in gewissen Epithelien, andererseits werden sie in Zellen vermisst, welche ganz zweifellos zur Bildung des collagenen Gewebes in nächster Beziehung stehen, wie z. B. im werdenden Bindegewebe des Kopfes und Schwanzes von Salamandra."

Ich habe mich selbst seit 1907 weiter mit den in Rede stehenden Fasern beschäftigt und will über die Resultate meiner Untersuchungen hier berichten. 
Die Fasern liegen in der Tat, wie Golowinski angibt, niemals im Protoplasma, sondern stets auf der Zelloberfläche. Von einer besonderen "Grenzschicht", wie Golowinski sie beschreibt, auf welcher die Fasern ihren Platz haben, vermag ich allerdings nichts wahrzunehmen. Sie lassen sich durch die gleichen Methoden wie die Chondrioconten darstellen, sind aber nicht, wie ich früher glaubte annehmen zu dürfen, mit solchen identisch. Sie unterscheiden sich von Chondrioconten sowohl chemisch als morphologisch: chemisch z. B. insofern, als sie durch die Zenkersche Lösung, welche die Chondrioconten auflöst, konserviert werden; morphologisch dadurch, dass die Chondrioconten Fadenstücke sind und sich auch da, wo sie auf der Zelloberflaiche liegen, niemals auf so weite Strecken über die Zellen und ihre Ausläufer erstrecken.

Chondriosomen habe ich in den Nabelschnurzellen des ausgetragenen Kindes überhaupt nicht aufgefunden; in denjenigen eines fünf- bis sechsmonatlichen Fetus dagegen sowohl Chondrioconten als auch zahlreiche Mitochondrien; letztere sind nicht zu verwechseln mit zum Teil viel grösseren Körnern und Schollen, welche durch die Fixierung mit Flemmingschem Gemisch gebräunt werden.

Über die Entstehung der epicellulüren Fasern habe ich bisher nichts ausmachen können, möchte aber glauben, dass sie aus Chondriosomen hervorgehen; von solchen stehen, wie gesagt, in den Zellen jüngerer Nabelschnüre ausser Körnern jedenfalls auch Fäden (Chondriokonten) zur Verfügung; ich möchte daher bezweifeln, ob die Beschreibung Golowinskis, welcher die epicellulären Fibrillen ausschliesslich aus Körnern entstehen lässt, unbedingt richtig ist.

Mit Merkel stimme ich gegenüber Flemming und Golowinski darin überein, dass die epicellulären Fasern mit der Bildung von collagenen Fasern nichts zu tun haben, den Namen "präcollagene Fasern", welchen Golowinski ihnen gegeben bat, also nicht verdienen. Ich habe ebensowenig wie M erkel jemals beobachtet, dass die fraglichen Fasern sich von den Zellen loslösen. Aber auch Fasern anderer Art habe ich in den von mir untersuchten jüngeren Nabelschnüren, von denen die jüngste aus dem fünften. Monat stammt, niemals von den Zellen frei werden sehen. Bilder, wie sie in dem Bindegewebe jüngerer Hühnerembryonen überall 
reichlich vorkommen: durch die Kollagenfürbemethoden darstellbare Fasern, welche auf der Zelloberflache gelegen oder in diese eingelagert sind, habe ich in den Nabelschnüren, die mir zur Verfügung standen, niemals aufgefunden. Daraus muss ich schliessen, dass eine Produktion von Bindegewebsfibrillen von den Zellen aus in der Nabelschnur mindestens vom fünften Monat an ebensowenig wie in älteren Sehnen stattfindet.

Was sind nun aber die epicellulären Fasern der Nabelschnurzellen? Ich vermag heute auf diese Frage zu antworten, dass sie mit den von Mallory (1903) sogenannten "Fibroglia"fasern identisch sind. Der Gedanke an eine Identitat beider Faserarten kam mir zuerst, wie ich die von Mallory (1904) auf Taf. VIII wiedergegebenen Figuren, besonders Fig. 2 betrachtete; als ich sodann die zur Darstellung der Fibrogliafasern empfollenen Methoden auf die Nabelschnur anwandte, zeigte es sich, dass die Fibrillen der Nabelschnurzellen die gleichen Reaktionen wie Fibrogliafasern geben.

Enter dem Namen. Fibroglia"fasern hat Mallory 1903 Fasern beschrieben, welche von den Bindegewebszellen neben collagenen und elastischen Fasern produziert werden und welche sich verschieden ron diesen, aber ähnlich wie die Fibrillen der glatten Muskelfasern färben. Die Fasern berühren nach Mallory mit der Mitte ihres Verlaufs die Oberfläche des Protoplasmas oder liegen eben unter derselben, auf einer kürzeren oder längeren Strecke in der Nachbarschaft des Kerns; es lässt sich nach Mallory nicht sagen, wie weit sie von Protoplasmafortsätzen begleitet werden. Sie verlaufen augenscheinlich von einer Zelle zur anderen, sodass diese sämtlich mehr oder weniger miteinander in Verbindung stehen.

M a ll ory fand diese Fasern reichlich unter pathologischen Verhältnissen in jeder Art von Bindegewebe, welches in lebhafter Wucherung begriffen ist. Im normalen Gewebe sind sie selten; jedoch hat Mallory sie im dichten Bindegewebe der Mamma, des Coriums und der spinalen Pia bemerkt. Reichlicher finden sie sich nach Mallory in den echten Basalmembranen verschiedener Drüsen, welche sie vielleicht ausschliesslich aufbauen (Harnkanälchen, Schweissdrüsen, Drüsenschläuche und Ausführungsgänge der Milchdrüse), sowie unter dem Endothel der Blutgefässe. Beim Embryo erscheinen sie (1903, S. 336) an gewissen Stellen, wo das Bindegewebe dicht ist, z. B. in der Umgebung von Knorpel, auf einem verhältnismässig frühen Stadium, d. h. mindestens ebenso früh, wie die Zellen der glatten Muskulatur ihre differentiell färbbaren Fibrillen erwerben. - M a ll or y möchte annehmen, dass die Fasern elastische oder kontraktile Eigenschaften besitzen.

Coca (1906), welcher sich die Aufgabe gestellt hatte, das Auftreten der Fibrogliafasern beim Hühnerembryo zu verfolgen, ist auf Grund seiner allerdings nur sehr spärlichen Befunde zu dem Schluss gekommen, dass die 
Fibroglia den embryonalen Vorläufer der collagenen Fasern darstellt; während Car olin e Mc Gill (1908), welche diese Fasern im Darm von Necturus direkt unter dem Epithel, wo sie eine Basalmembran bilden, und im subepithelialen Bindegewebe verstreut auffand, der Meinung ist, dass sie als eine Art von Myofibrillen angesehen werden müssen.

Ich möchte glauben, dass Fibrogliafasern von gleicher Mächtigkeit und Zahl wie sie in der Nabelschnur des ausgetragenen Kindes vorkommen, nicht so leicht irgendwo wiederzufinden sein werden. Über ihre Bedeutung ist es schwer, etwas bestimmtes auszusagen; nach meiner Meinung handelt es sich um einen „Bestandteil der Protoplasmastrulktur“, welcher mit den bei den glatten Muskelfasern aufgefundenen Grenzfibrillen (M. Heid enhain, 1901, 2) oder Myogiiafibrillen (Benda, 1902) nicht nur "vergleichbar“ (Merkel), sondern sogar identisch ist. Fibrogliaund Myogliafasern sind nämlich nicht nur, wie Mallory bereits konstatiert hat, färberisch auf keineWeise zu unterscheiden, sonder"n zeigen auch in morphologischer Beziehung völlige Übereinstimmung. Sie verlaufen beide an den Stellen ibres Vorkommens auf der Oberfläche und in der Längsrichtung der Zellen. „Eine eigentliche Endigung, die einem Zellende entspräche“, welche Benda bei den Myogliafasern vermisst, kommt auch bei den Fibrogliafasern nicht vor; beide ziehen vielmehr in grösserer Ausdehnung kontinuierlich über eine Reihe von Zellen. Was B enda (1902, S. 216) von den glatten Muskelfasern scbreibt: „Die einzelnen Zellbezirke sind nur an den eingesprengten Kernen $z u$ schätzen; wăhrend die seitlichen Zellgrenzen scharf hervortreten, sind die longitudinalen Zellenden völlig verschwunden bezw. von den Fasern verdeckt", könnte ebensogut von den Nabelschnurzellen gesagt werden.

Wührend ich also bezüglich dieser epicellulären Fasern im wesentlichen mit Merkel übereinstimme, teile ich durchaus nicht seine Ansicht, dass die Fasern, welche Flemming bei den Bindegewebszellen der Salamanderlarve beschrieben hat, in dieselbe Kategorie gehören. Merkel (1909, S. 362) glaubt epicelluläre Fasern der gleichen Art in Flemmings Zeichnungen von Salamanderzellen wiederzuerkennen; in Zellen, deren Teilung sich dem Ende nähert, würden sie eng zusammengefasst und gingen über die Einschnürungsstelle hinweg von einer Tochterzelle in die andere über; in einer Abbildung Flemmings (1891, Fig. 3, wiederholt 1902, Fig. 3), strahlten sie nach der unmittelbar vor der Trennung stehenden Teilungsstelle zusammen. Bei den hier 
von Merkel bezeichneten Fasern dürfte es sich nun aber um solche der achromatischen Spindel handeln, die im Zwischenkörperchen zusammengefasst sind. Diese liegen sicher intracellulär, sind jedoch gar nicht diejenigen, welche Fle mming bei seiner Beschreibung im Auge gehabt hat. Letztere sind nach Flemming ebenfalls, wenigstens bei sich teilenden Zellen, „unverkennbar" im Zellkörper gelegen; sie erscheinen, wie Flemming hinzufügt, bei derselben Einstellung, bei der man auch die Fasern der Polstrahlung sieht. Meines Erachtens kann es sich bei diesen Fasern nur um Chondrioconten gehandelt haben.

Hansen (1899) beobachtete in den tieferen, weicheren Partien der Intervertebralscheiben von Kalbsfeten viele Zellen, die noch nackte Bindegewebszellen sind, in deren Protoplasmakörper und Zellausläufern sich reichliche collagene Bindegewebsfibrillen entwickelt hatten, welche teilweise frei in die umgebende Grundsubstanz hinausragten. Ich kann demgegenüber nur wiederholen, dass ich die jungen Fibrillen immer nur auf der Oberfläche oder in der oberflächlichsten Plasmaschicht der Bindegewebszellen gefunden habe. - Nach Hansen (1905, S. 771) kann man ferner in vielen Knorpeln, noch häufiger aber im gewöhnlichen Bindegewebe beobachten, dass Fila des Protoplasmas sich direkt in Bindegewebsfibrillen der Grundsubstanz fortsetzen. Mit Bezug auf diese Angabe, die sich schon bei Spuler (1896) findet, habe ich oben bereits konstatiert, dass ich niemals eine Kontinuität zwischen einem Protoplasmafaden und einer Bindegewebsfibrille gesehen habe.

Es ist hier nicht der Ort, über die verschiedenen Formen der Collagenbildung im Knorpel, welche $\mathrm{H}$ ansen beschreibt, zu berichten. Ich kann aber nicht umhin, zu bemerken, dass mir seine Schilderungen zum Teil etwas problematisch vorkommen; z. B., wenn er ganze Zellen in Fibrillen zerfallen lässt, indem sie sich in "Albumoid", eine hypothetische Vorstufe von Collagen oder Elastin, umwandeln.

Mit Bezug auf das "Ectoplasma" von Hansen verweise ich auf meine Bemerkungen zu der Arbeit Studničkas sowie auf den Schluss.

Nach Studnička (1903) "bilden sich“ in den Zellen und ihren Fortsätzen zunächst feine Fasern oder Fibrillen, die als 
die ersten Andeutungen (Vorstufen) der collagenen Fibrillen anzusehen sind. Diese Fasern treten zuerst im ganzen Innern der Zellen ohne Unterschied auf. Später erscheint um den Kern herum eine „Partie eines reinen Protoplasmas"; die Fibrillen konzentrieren sich jetzt hauptsächlich auf die Peripherie der Zellen. „Der ganze Zellkörper wird in ein Endoplasma, das den Zellkern umgibt, und das die Fibrillen enthaltende Exoplasma geteilt." Beide Plasmaarten sind aber anfangs durch keine scharfe Grenze voneinander getrennt; eine solche erscheint erst spater „um das Endoplasma, das sich dadurch in die eigentliche Bindegewebszelle verändert". Auch die "Gesamtzellen" weisen nach Studnička keine äussere scharfe Grenze auf. Ihre OberHaiche sieht wie zerfasert aus. Es scheint, als ob sich das fibrillenhaltige Exoplasma auf der Zelloberfläche auflöst und als $o b$ dadurch die Fibrillen frei zu liegen kommen. In günstigen Fällen kann man sich aber davon überzeugen, dass von einer wirklichen Autlösüng nicht die Rede sein kann, sondern dass "das stark und wie schleimartig veranderte Exoplasma als die Interfibrillärsubstanz, die eigentliche Grundsubstanz des Gewebes erhalten bleibt".

Ich behaupte nun gegenüber Studnička zunächst, dass die Fïden, welche die Vorstufen der collagenen Fasern sind, sich nicht erst bilden, sondern von vornherein in den Zellen vorhanden sind. Ferner habe ich weder bei den Zellen der Sehne noch auch bei anderen Bindegewebszellen, z. B. denjenigen des Periosts, des Coriums, des Subcutangewebes, von einer Sonderung des Protoplasmas in zwei Zonen oder von einer "Verschleimung" der Zellobertläche irgend etwas wahrnehmen können. Was Merkel (1909, S. 358) von den Zellen der Nabelschnur sagt, gilt auch von denjenigen des embryonalen Bindegewebes beim Hülınchen: „Die Zellen sind gegen die Umgebung durchaus scharf abgegrenzt und kein unbefangener Beobachter wird daran zweifeln, dass nirgends Übergänge des Zellprotoplasmas in die Gallerte vorhanden sind, was man bei vorhandener exoplasmatischer Umwandlung doch wenigstens gelegentlich beobachten müsste".

Ich schliesse mich daher denjenigen Autoren an, welche die Existenz eines „Exoplasmas" im Sinne von Studnička in Abrede stellen. 
Spalteholz (1906, S. 213) tritt ebenfalls für eine intracelluläre Entstehung der collagenen Fasern ein; er findet "auch in etwas späteren Stadien die Fasern immer von einer Protoplasmahülle in Gestalt feiner Granula begleitet", was ich meinerseits nicht bestätigen kann.

Maximow (1906, S. 688) beschreibt im lockeren Bindegewebe von Säugetieren „Fibroblasten“, deren Protoplasma bei supravitaler Farbung mit Neutralrot fast homogen erscheint, „mit feinster, blasser Körnelung, die vielleicht der Ausdruck eines netzigen Baues ist". "In den Endabschnitten der Ausläufer ist die Körnung kaum sichtbar - hier treten dafür mitunter feinste Längsfasern auf, die in die Zwischensubstanz überzutreten scheinen." „Es können aber auch“, wie Maximow fortfährt, „feinste von aussen dem Zelleib anliegende Collagenfüserchen sein".

Nach Wera Dantschakoff (1908, S. 148) gelingt es mit Hilfe der Malloryschen Methode im embryonalen Mesenchym des Hühnchens „dort, wo die Zellen naher aneinander gelagert erscheinen, die Bildung der ersten Collagenfasern im Protoplasma der Zellausläufer selbst zu verfolgen."

„Am schärfsten treten sie in den von den Zelleibern entfernteren Teilen der Ausläufer auf. In der Richtung nach dem Zelleibe werden sie weniger deutlich, sie verschwimmen hier und verlieren sich allmählich im Zellprotoplasma. An einigen Zellausläufern sieht man die Collagenfasern hart am Rande derselben auftreten, sodass hier das Protoplasma von feinen scharfen Konturlinien umsäumt erscheint. In der Folge isolieren sich solche Fibrillen vom Protoplasma, sie spalten sich von ihm gewissermassen ab. In manchen Fällen zerfällt die ganze Masse eines Zellausläufers in einen Strang parallel verlaufender und wellenförmig gebogener Fibrillen."

r) Die Bindegewebsfibrillen entstehen aus einer von den Zellen gebildeten formlosen Substanz (Merkel, v. Ebner, Retterer, Mall, Renaut, Laguesse, Bruni).

Merkel war durch Beobachtungen an der Nabelschnur (1893 und 1895) und den Fingersehnen menschlicher Embryonen (1895) zu der Auffassung gekommen, dass die Bindegewebsfibrillen sich aus einer Gallertsubstanz bilden, welche durch die Tätigkeit der Zellen ausgeschieden wird und welche dann fibrillär zerfällt. Dieses Resultat konnte er 1909 auf Grund von ausgedehnten eigenen Studien, welche an einem hauptsächlich in 
Embryonen von Amphibien und Säugetieren bestehenden Material angestellt waren, und denjenigen anderer Untersucher in folgender Weise vervollständigen $(1909$, S. 379 u. folg.):

Das Zellsyncytium des Mesenchyms "scheidet eine amorphe Gallertsubstanz aus, welche entweder nur spärlich (Sehnen, reticuläres Bindegewebe der lymphoiden Organe) oder in grösserer Menge, selbst reichlich vorhanden ist (Amphibien, Nabelschnur)". „Sie erfüllt dann die Lücken des Zellnetzes, kann sich sogar relativ weit über dasselbe binaus erstrecken, ohne dass Zellen ihr folgen (Muskeln). Überall, wo die Gallerte mit anderen Geweben zusammenstösst (Epithelien und ihre Derivate, Muskeln, Nerven), verdichtet sie sich zu einer amorphen Grenzschichte (membrana terminans, Umhüllung der Muskel- und Nervenfasern)."

„Im Innern des Bindegewebes selbst nehmen die Zellen an der Bildung der Fasern ebenfalls keinen direkten Anteil, dieselben entstehen vielmehr ausschliesslich in der Gallerte, die Zellen dienen nur zur Erzeugung dieser letzteren. Die Faserstruktur tritt in der Gallerte meist als ein indifferentes, sehr zartes Netz in die Erscheinung, welches erst in der Folge durch Zerreissen der weniger beanspruchten Fuden zu glatten und unverzweigten Fasern umgewandelt wird. Die Faserbildung erfolgt entweder direkt in der Gallerte oder in Lamellen, welche sich zuvor aus liasor absohoidon."

"An Stellen, an welchen gleich von Anfang an eine ausgesprochene Spannung vorhanden ist (Sehnen), wird das netzförmige Stadium nicht durchgemacht, sondern es kommt sogleich zur Bildung parallel verlaufender, unverzweigter Fasern."

"Die fertigen Bindegewebsfasern sind also in jedem Fall lediglich die Folge mechanischer, auf die Gallerte oder die in ihr entstehenden Lamellen einwirkender Verhältnisse."

„Bei ihrem ersten Auftreten sind die Fasern noch nicht collagen, sie sind auch zumeist noch nicht glatt und glänzend wie echte Bindegewebsfasern, man findet sie vielmehr noch körnig, nicht selten varicös. Erst später, wenn auch oft schon sebr zeitig, nehmen sie das vom fertigen Bindegewebe her bekannte Aussehen an."

v. Ebner (1896) studierte die Bildung der Chordascheide bei niederen Fischen. Er konstatierte, dass die ersten Fibrillen in direktem Kontakt mit den Epithelzellen der Chorda an deren 
äusserer Oberfläche als zirkulär um die Chorda verlaufende Fäserchen auftreten, fand es aber schwierig, ,eine genauere Vorstellung von dem histogenetischen Vorgange der Fibrillenbildung auf Grund direkter Beobachtung zu geben". „Ich habe mich bemüht", sagt er S. 512, "mit den stärksten Vergrösserungen an der Oberfläche der Zellen etwa die Bildung der Fibrillen aus Körnchen zu verfolgen, aber stets vergeblich. Xan sieht wohl eine feinkörnige Oberfläche der Zellen, welche bei grösseren Tieren wie ein gestrichelter Saum erscheint, aber keine Zwischenformen von Körnern und Fasern oder gar eine Ausscheidung von Fibrillen aus dem Zellinnern. Die Fibrillen erscheinen als kontinuierliche, feine, glatte Fadchen, sobald sie überhaupt erkennbar werden."

Wir sind daher nach v. Ebner auf mehr spekulative Erörterungen angewiesen. Roux hat aus seinen Untersuchungen über die Schwanzflosse des Delphins bereits den Schluss gezogen, dass zur Fibrillenbildung wahrscheinlich von aussen her erzeugte Zugspannung nötig sei. Halt man an dieser Vorstellung fest, so liegt der Gedanke nahe, dass die leimgebenden Bindegewebsfibrillen aus leimgebender Substanz entstehen, welche zunächst als nicht fibrilläre, colloidale Masse von den Zellen gebildet und dann unter dem Einflusse orientierter Zug- oder Druckspannung zu bestimmt geordneten Fibrillen geformt wird. "Wie wir mit Roux bei aller Entwicklung die Momente der Selbstdifferenzierung und der Korrelation auseinander zu halten haben, so können wir auch hier an ein Ineinandergreifen dieses doppelten elementaren Geschehens denken, indem zwar wohl die Bildung der leimgebenden, nicht aber ihre fibrilläre Ausscheidung als eine rein celluläre, von den inneren Bildungskräften des Protoplasmas ausgehende Erscheinung wăre."

An dieser Vorstellung glaubt v. Ebner auch in einer weiteren Abhandlung (1906) festhalten zu sollen, in welcher das "prinzipielle Problem der Fibrillenbildung" noch einmal eingehend besprochen wird.

Retterer resumiert 1902, S. 198 seine Anschauungen über die Histiogenese des Bindegewebes, zu welchen er durch frühere (daselbst zitierte) Arbeiten gekommen ist. Die gemeinsame Anlage aller Arten von Bindegewebe wird nach ibm durch eine protoplasmatische Masse dargestellt, welche zahlreiche Kerne 
enthält. Diese Masse differenziert sich in ein die Kerne einschliessendes Netzwerk färbbarer Fäden (réticulum chromophile), dessen Maschen mit "homogenem Protoplasma“ oder "Hyaloplasma" angefüllt sind. Das Hyaloplasma, welches früher abwechselnd als Blastem, Grundsubstanz, Intercellularsubstanz beschrieben worden ist, entwickelt sich stärker als das Reticulum. Später wird es mehr konsistent und beginnt eine Streifung zu zeigen, welche immer deutlicher wird; schliesslich kommen parallel gerichtete collagene Fibrillen von welligem Verlauf zum Vorschein.

If all, welcher früher $(1891$, S. 326) aus seinen Beobachtungen schliessen musste, dass die Fasern des Bindegewebes in allen Stadien der Entwicklung intercellulär sind und dass sie durch eine Art Gerinnung abgeschieden werden, kam 1902, als er die Fibrillenbildung bei Froschlarven und Schweineembryonen studierte, zu einem wesentlich anderen Resultat. Er beschreibt, dass die mehr vereinzelten Zellen, aus denen das Mesenchym bei sehr jungen Froschlarven besteht, weiterhin an Protoplasma zunehmen, sich mit ihren Ausläufern vereinigen und auf diese Weise ein dichtes Syncytium bilden. Die Protoplasmabrücken des Syncytiums verdicken sich alsdann zu breiten Bändern. Noch später differenziert sich das gesamte Protoplasma in ein Exoplasma, welches die Hauptportion des Syncytiums bildet, und die den Kern umgebenden Endoplasmen. Das Exoplasma spaltet sich, wenn ich die Beschreibung von Mall richtig verstehe, in eine Anzabl von Fäden, die "Exoplasmafibrillen"; die Endoplasmen mit ihren Kernen liegen auf Bündeln von anastomosierenden Exoplasmafibrillen. Die Exoplasmafibrillen spalten sich schliesslich ihrerseits (unter Zerreissung der zwischen ihnen bestehenden Anastomosen) in die einzelnen collagenen Fibrillen.

Renaut (1903, 1 und 2) beschreibt im lockeren Bindegewebe und im Netz von Säugetieren einen "Einschlag" (tramule) feinster Fäden; diese sollen sich aneinanderlagern, um die Bindegewebsbündel zu bilden.

Die Beziehungen dieser Fäden zu den Zellen hat Renaut am nicht durchlöcherten Netz junger Tiere studiert; er findet sie von sehr unbestimmter Art, sowohl zu den Endothelien als auch zu den echten Bindegewebszellen. Wenn daher die Zellen überhaupt einen Einfluss auf die Entwicklung der Fäden haben, 
was ausserordentlich wahrscheinlich ist, so bleibt nichts übrig, als anzunehmen, dass die Zellen durch „tangentielle Differenzierung“ derselben entstehen („mais sans provenir toutefois d'une transformation directe de partie de ceux-ci", 1903, 1, S. 21).

Lag u ess e (1903-04) findet, dass dem Auftreten der Bindegewebsfaser immer die Bildung einer formlosen Substanz vorausgeht, in welcher sie entsteht. Die Bindegewebsfaser ist nichts anderes als diese Substanz selbst, welche die letzte Stufe chemischer Umwandlung erreicht hat und, wahrscheinlich unter dem Einfluss mechanischer Ursachen, fibrillär geworden ist.

Für diese Ansicht stützt sich Lagues s e auf Beobachtungen, die er an der Kapsel der Selachiermilz sowie an den lamellösen Bildungen des Bindegewebes bei Säugetieren gemacht hat.

Die Kapsel der Selachiermilz besteht nach Laguesse (1903, 1 und 2) aus zwei eng verbundenen Lagen von Bindegewebsfasern. Die oberflachlichen Fasern gehören der Serosa an, liegen unter dem Endothel derselben und entwickeln sich innerhalb einer zarten formlosen Glashaut, welche ihrerseits das Produkt einer hautartigen Zellenlage ist, die das Milzreticulum abschliesst. In gleicher Weise entstehen auch die Fasern der tieferen Schicht durch eine Art Verdichtung und Differenzierung innerhalb von Zügen einer formlosen „präcollagenen" Substanz. Diese letztere wird im allgemeinen von den Zellen auf Kosten der oberflächlichen Schichten des Cytoplasmas gebildet; es können aber auch ganze Zellfortsătze und sogar ganze Zellen in "Prăcollagen" umgewandelt werden.

Beim Studium der lamellösen Bildungen des Bindegewebes ging Laguesse von den feinen Häutchen aus, welche das lockere intermusculäre Bindegewebe beim Pferd zusammensetzen $(1903,3)$. Diese erscheinen an Flächenpräparaten, nach Fixierung in absolutem Alkohol und Färbung mit Pikrofuchsin, von gespannten Bindegewebsfibrillen durchzogen, welche häufig durch ein Maschenwerk sehr feiner Fasern (nach Art des Renautschen Einschlags) verbunden werden. Die Fasern liegen eingebettet in eine formlose Grundsubstanz, welche, obwohl nur schwach rötlich gefärbt, dennoch sehr deutlich ist.

In einer weiteren Mitteilung $(1904,1)$ hat Laguess e diese Lamellen auch an Schnitten und ausserdem an einer anderen Stelle, im Unterhautbindegewebe von Ratten, untersucht. 
An letzterem Objekt hat er schliesslich noch die embryonale Entwicklung der Lamellen verfolgt $(1904,2)$. Bei Rattenembryonen von $11^{1 / 2}-12 \mathrm{~mm}$ (vom 15. Tag) besteht das Subcutangewebe an der Seitenfläche des Thorax aus sternförmigen miteinander anastomosierenden Zellen. Die fast hyalin erscheinenden Fortsätze derselben zeigen schon jetzt eine gewisse Vorliebe für Pikrofuchsin (Hansensche Methode); nach Laguesse sind sie bereits auf dem Wege, sich in Exoplasma zu differenzieren. Später macht sich mehr und mehr eine bestimmte Orientierung der Mesenchymbalken bemerkbar; diejenigen von ihnen, welche in einer Ebene parallel der Hautoberflache liegen, verbreitern und verstärken sich und verschmelzen untereinander; die übrigen dagegen bleiben zart und scheinen häufig zu zerreissen. Auf diese Weise bilden sich eine Reihe von Lagen, eine über der anderen, welche beinahe regelmässig parallel, aber sehr häufig durch schiefe Anastomosen vereinigt sind. Bei Embryonen von $17^{1 / 2}-18 \mathrm{~mm}$ (vom 18. Tag) zählt man zirka 30 davon. In jeder dieser Lagen ist die exoplasmatische Differenzierung beendigt und man unterscheidet sehr deutlich einerseits sehr feine, rötlich gefärbte, fast homogene Lamellen, andererseits feinkörnige Zellen, Endoplasmen, welche von den Lamellen frei geworden sind und sich auf ihrer Oberfläche unter Abplattung ausgebreitet haben. Ihr Zellkörper ist grösser als vorher, ihre Form polygonal, sternförmig oder spindelförmig. Die Zellen überkleiden die Lamellen nicht kontinuierlich, sondern anastomosieren hier und da mittels sehr feiner körniger Fortsätze. In den Lamellen sind sehr zahlreiche und feine in der Entwicklung begriffene Fibrillen eingeschlossen.

Nach Bruni (1909) sind in der Entwicklung der Zwischenwirbelscheibe beim Rindsembryo zwei Perioden zu unterscheiden. Wahrend der ersten entstehen die leimgebenden Fasern ausschliesslich in der intercellulären Grundsubstanz, während der zweiten ebenhier und ausserdem im Zellkörper. Die Grundsubstanz ist nicht als ein formloses und inertes Sekretionsprodukt, sondern als Ectoplasma oder als Metaplasma im Sinne M. Heidenhains, d. h. als mehr oder weniger differenzierte Zellsubstanz aufzufassen. 
Zur Kritik der von Merkel, v. Ebner, Retterer, Mall, Renaut, Laguesse, Bruni erhaltenen Resultate möchte ich zunächst bemerken, dass diese Autoren die intracellulären Fäden nicht gekannt haben und in Folge davon auch nicht als Ursprungsquelle für die Bindegewebsfasern berücksichtigen konnten. L a g u e ss e (1903, 2, S. 162) erklärt geradezu, er könne nicht glauben, dass jede Fibrille direkt aus einem Faden des Mitoms hervorginge: "d'autant moins que nous ne sommes nullement convaincu de l'existence nécessaire, en toute cellule, d'une pareille structure cytoplasmique ${ }^{*}$.

Alle genannten Autoren stimmen darin überein, dass sie die Bindegewebsfasern aus einer formlosen Substanz entstehen lassen. Von der Existenz einer solchen, soweit es sich nicht um die ungeformte Intercellularsubstanz handelt, habe ich mich nun aber niemals überzeugen können.

Die "amorphe Gallerte" Merkels ist meines Erachtens weiter nichts als eben diese ungeformte Intercellularsubstanz (die „homogene Grundsubstanz" Sch iefferdeckers, die „Kittsubstanz" Schaffers), welche bereits vor dem Auftreten der Fibrillen vorhanden ist. In dieser habe ich häufig zarte Netzstrukturen beobachtet, hatte aber stets den Eindruck, dass es sich dabei um Gerinnungen oder Niederschläge handelte, welche durch die Fixierungsmittel erzeugt waren. Ich glaube also, dass der Argwohn, welchen Merkel selbst (1909) diesen Netzstrukturen gegenüber an verschiedenen Stellen seiner Abhandlung aussert, nur zu berechtigt war.

Dafür, dass diese ungeformte Intercellularsubstanz als metamorphosiertes Zellprotoplasma aufzufassen sei, wie es Retterer und Bruni wollen, scheint es mir an jedem Beweis zu fehlen. Ich teile bezüglich ihrer die Anschauung Sch affers (1901), dass sie von den Bildungszellen in tlüssiger Form ausgeschieden wird ${ }^{1}$ ).

Von dem Exoplasma Malls gilt nach meiner Meinung dasselbe wie von demjenigen $S t u d n i c ̌ k a s:$ dass die Beobachtungen, welche zu seiner Aufstellung geführt haben, irrtümlich sind.

1) Nach Sch a ffer (1901, S. 100) müssen diejenigen Autoren, welche die Bindegewebsfibrillen innerhalb des Körpers der Bildungszellen entstehen

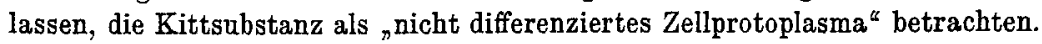
Warum sie dies müssen, vermag ich nicht einzusehen; ich selbst fasse sie jedenfalls durchaus nicht in dieser Weise, sondern ebenso wie Schaffer auf. 
Ebenso bin ich bezüglich der „präcollagenen Substanz ${ }^{\prime}$ von Laguesse bei einer Nachuntersuchung am Unterhautbindegewebe des Hühnchens zu einer wesentlich anderen Auffassung gelangt.

Die Tatsache, dass sich feine und feinste Protoplasmaverzweigungen bei den spezifischen Bindegewebsfärbungen mit dem "collagen" färbenden Farbstoffe, wenn auch nie so intensiv wie wirkliche leimgebende Fibrillen (mit Pikrofuchsin blassrot), färben, ist auch von v. Ebner (1906, S. 27) konstatiert worden. Man ist daraufhin aber nicht berechtigt, von einer "exoplasmatischen Differenzierung "von Zellausläufern, wie Laguesse es tut, zu reden.

Lamellöse Bildungen des Subcutangewebes habe ich oben selbst vom Hühnchen beschrieben und in den Fig. 3 und 6 abgebildet. Von einer Differenzierung der sie zusammensetzenden Zellen in ein Endo- und Exoplasma habe ich aber nichts wahrgenommen. Die Bindegewebsfasern des Subcutangewebes entwickeln sich nach meinen Beobachtungen nicht in den Lamellen, wie Laguesse angibt, sondern auf ihrer Obertlache aus Chondrioconten, welche hierhin verlagert worden sind. Was Laguesse als Exoplasma oder "präcollagene Substanz" der Lamellen beschreibt, sind die flachenhaft ausgebreiteten hellen Leiber der Zellen, welche die Lamellen zusammensetzen.

Ich bitte um Entschuldigung, wenn ich auf Grund dieses Resultats meiner Nachuntersuchung am Subcutangewebe geneigt bin, auch die Ergebnisse, zu denen Laguesse an der Kapsel der Selachiermilz gelangt ist, skeptisch zu beurteilen.

v. Ebner hat die Meinung ausgesprochen, dass die Bildung der Bindegewebsfibrillen durch das Vorhandensein einer orientierten Spannung hervorgerufen wird. Mehrere Autoren, z. B. Merkel und Laguesse, baben sich dieser Vorstellung angeschlossen. v. Ebner selbst verkennt allerdings nicht die Schwierigkeiten, welche ihr entgegenstehen: „Es ist vorläufig nicht möglich, direkt nachzuweisen, dass tatsächlich während der Bildung der Fibrillen die theoretisch geforderten Spannungen bestehen, und es sind nur Wahrscheinlichkeitsgründe, die man dafür geltend machen kann" (v. Ebner, 1906, S. 56).

Meine Beobachtungen zeigen nun aber, dass eine derartige Anschauung, soweit die erste Entstehung der Fibrillen in Frage 
kommt, nicht aufrecht erhalten werden kann. Die Sehne ist. nach Merkel (1909, S. 380) eine Stelle, an welcher „gleich von Anfang an eine ausgesprochene Spannung vorhanden ist". Wir haben aber gesehen, dass die Bindegewebsfibrillen hier von vornherein, sobald sie überhaupt erkennbar werden, einen welligen Verlauf zeigen; während sie, wenn sie sich unter Einwirkung einer Spannung entwickelten, von Anfang an gestreckt sein müssten. Da ich die zur Untersuchung verwandten Hühnerextremitäten stets eine Strecke weit oberhalb des Hüftgelenks vom Körper abgetrennt habe, halte ich es für ausgeschlossen, dass die Wellenbiegungen der Fibrillen etwa nur die Folge einer beim Abschneiden aufgetretenen "Entspannung" sein könnten.

\section{Schluss.}

Die oben geschilderten Befunde an der sich entwickelnden Sehne zeigen in unzweideutiger Weise, dass die Fibrillen, nachdem sie einmal gebildet sind, selbstandig sowohl in die Länge als auch in die Dicke weiter wachsen.

Dass Bindegewebstibrillen unabhängig von Zellen in die Länge wachsen, ist zuerst von $v$ Ebner in einer am 31. Dezember 1896 ausgegebenen Abhandlung (auf deren Inhait ich bereits oben eingegangen bin) nachgewiesen worden. v. Ebner findet, dass bei Ammocoetes die drei Schichten, aus denen die Chordascheide sich aufbaut, sich unter Vermehrung und Verlängerung der Fibrillen weiter entwickeln, nachdem sie längst jeden direkten Kontakt mit den Bildungszellen verloren haben. Die Fibrillen wachsen nach v. Ebner in die Länge, "nicht in der Art eines Krystalles, sondern durch Intussusception, durch Aufnahme neuer Teilchen leimgebender Substanz zwischen die alten". Die Vermehrung dagegen besteht nach demselben Autor in einer extracellulären Neubildung, welche in der bereits oben gesehilderten Weise erfolgt: auf Kosten einer leimgebenden Substanz, welche zunăchst als nicht fibrilläre, colloidale Masse von den Zellen abgesondert, dann aber unter dem Einfluss orientierter Zug- oder Druckspannung $\mathrm{zu}$ bestimmt geordneten Fibrillen umgeformt wird. v. Ebner bemerkt aber S. 520, man könnte auch denken, „dass die Neubildung von Fibrilten durch Längsteilung der bereits vorhandenen geschehe"; "und da andererseits der An- 
nahme in unserem Fall nichts im Wege steht, dass die ersten Fibrillen durch direkte Bildung aus der Oberflächenschicht der Chordaepithelzellen hervorgehen, so würde damit den herrschenden Anschauungen besser Genüge geschehen als durch die früher aufgestellten Annahmen. Da darüber, ob die Fibrillen sich teilen oder nicht, durch direkte Beobachtung keine Entscheidung getroffen werden kann, weil Anfang und Ende der Fibrillen, sobald sie einmal da sind, nicht mehr verfolgt werden können, wird vielleicht mancher Leser diese Vorstellung als immerhin mögliche und in die herrschenden Lehren von der Strukturbildung besser passend bevorzugen".

Diejenige Vorstellung, welcher v. Ebner hier, so viel ich weiss, zum ersten Mal Ausdruck verleiht, „dass die Neubildung von Fibrillen durch Langsteilung der bereits vorhandenen geschehe" (welche er aber selbst zugunsten einer anderen verwirft), ist dann von Flemming in zwei Publikationen des Jahres 1897 vertreten worden.

In der ersten Abhandlung $(1897,1)$ sagt Flemming am Schluss (S. 186), dass er sich die Bindegewebsfibrillen nach ihrer Anlage keineswegs als eine tote oder inerte Substanz denke, ebensowenig wie er diese Auffassung von den Intercellularsubstanzen überhaupt habe. "Nach dem hier Dargelegten und anderem scheint mir allerdings die Annahme berechtigt, dass die Fibrillen stets im Zellenleib entstehen und jede weitere Produlition ein Nachschub von dieser Seite ist. Wir wissen (aber) selbst dies nicht bestimmt, $d$. h. wir wissen nicht, $o b$ die zunächst cellulär gebildeten Fibrillenmassen nicht etwa auch eigene Wachstumsfähigkeit mit bekommen und sogar ihre Fasserchen vermehren können. Denn was hier entsteht, ist eben doch nur ein metamorphosierter Teil des Zellenleibes, der als Territorium eigentlich. zu diesem Leibe zu gehören fortfăhrt; es ist in keiner Weise auszuschliessen, dass ihm, also der Intercellularsubstanz, eigener Stoffwechsel, eigene Umwandlungs- und Vermehrungsfähigkeit zukommt. Wenn man die Wachstumserscheinungen der elastischen Fasern ansieht, so scheint mir solche Annahme sogar mit Notwendigkeit gemacht werden zu müssen; sie verdicken sich und wachsen vielfach, wie man zu sagen plegt, durch Intussusception, ohne dass irgendwie ersichtlich wäre, dass diese Vergrösserung durch die Tätigkeit einer Zelle erfolgte. Was für die elastischen 
Fasern gilt, kann möglicherweise auch für die collagenen Faserbündel gelten; jedenfalls das, dass sie und ihre Zwischensubstanz fortfahren zu leben und Stoffwechsel haben, wie die Zelle, von der sie produziert sind und von der sie eigentlich doch ein integrierender Teil bleiben. Insofern, allerdings auch nur insofern, kann man Grawitz' bekannte Anschauungen über die Intercellularsubstanzen motiviert finden."

Mit viel grösserer Bestimmtheit hat sich Flemming für die gleiche Anschauung im Kap. VIII (Intercellularsubstanzen) eines im selben Jahre in den Merkel-Bonnetschen Ergebnissen erschienenen Berichts über Morphologie der Zelle $(1897,2)$ ausgesprochen.

Wenn ich vertrete, sagt er hier S.262, dass die ersten Fibrillen im Leib der Bindegewebszellen selbst, wenn auch möglicherweise immer in ihren peripheren Teilen entstehen, so ist "hierunter durchaus nicht zu verstehen, dass ich mir denke, Bindegewebsfibrillen mïssten immer in eigentlichen Zellenleibern gebildet werden. Es scheint in der Tat vielfach gedacht zu werden, dass es in dieser Frage nur eine Alternative gebe: entweder die Fibrillen entstehen in einer Zelle oder a usserhalb derselben. So verstehe ich die Sache durchaus nicht. Ich meine vielmehr: es bildet sich im peripheren Teil der Zelle eine fibrillenhaltige Schicht, diese Schicht wird Intercellularsubstanz, wachst an Masse und kann immer neue Fibrillen produzieren, so lange sie eben wachst. Ich denke mir, mit anderen Worten, die Intercellularsubstanz nicht tot oder doch inert, wie es manche tun, sondern ich denke sie mir als eine von den Zellen produzierte, wohl strukturell und chemisch abgeänderte, aber lebendige Masse, welche auf längere Zeit das Vermögen behält, Fibrillen zu formen. Ohne diese Annahme liesse es sich, wie mir scheint, gar nicht verstehen, dass man im Wirbeltierkörper vielfach noch in späten Stadien des Wachstums die Fibrillenbündel an Orten in starker Vermehrung findet, wo die Zellen verhäItnismässig spärlich sind."

"Unter dieser Annahme", fährt Fl le m ming fort, ,verschwindet auch, wie mir scheint, jeder wesentliche Gegensatz zu den Angaben, die $\mathbf{v}$. E b n er iiber die Fibrillenbildung in der Chorda dorsalis vor kurzem gemacht hat. Ich möchte nur auch hier die Möglichkeit in Anspruch nehmen, dass die erste 
Bildung fibrillenhaltiger Intercellularsubstanz von den Zellen ausgeht. Dass diese Intercellularsubstanz in sich selbst neue Fibrillen hervorbringen. kann, bezweifle ich durchaus nicht."

Flemming bespricht sodann an der genannten Stelle einen Aufsatz v. Köllikers (1897), in welchem dieser daran festhält, dass die bindegewebigen fibrillären Intercellularsubstanzen „nicht durch eine direkte Umwandlung von Protoblasten (alsoZellen), sondern durch Abscheidungen von solchen, ähnlich der Cutikularbildungen, entstehen. v. Kölliker stützt dies besonders darauf, dass nach seinen Beobachtungen die osteoide Substanz (Skelett und Schuppen vieler Fische) weder bei ihrer Entwicklung, noch fertig jemals Zellen oder Protoblasten zeige, und dass, wie v. Ebner beschrieben habe, die Fibrillen des Zahnbeins parallel zur Achse des Zahns, senkrecht zum Verlauf der Odontoblastenauslaufer gerichtet seien, worin ein Beweis liege, dass sie nicht aus diesen entstehen. F l e m ming bemerkt hierzu, dass v. Köllikers Meinung und die seinige nicht so weit auseinander gingen, als es auf den ersten Blick scheinen möge. "Ich zweitle ja durchaus nicht", sagt er, "dass die einmal gebildete fibrillare Zwischensubstanz in sich selbst weiter wachsen und neue Fibrillen bilden kann, eben weil ich sie für einen metamorphosierten Teil von Zellenleibern halte. So mögen die Fibrillen in der osteoiden Substanz und im Zahnbein gern eine derartige sekundäre Entstehung haben. Aber ich glaube auf Grund meiner ubjekte allerdings, dass die erste Bildung tibrillärer Substanz von Zellenleibern ausgeht; und möchte es für möglich halten, dass die Untersuchung der fir ühesten Stadien der Fibrillenentwicklung in den Fällen, die v. Kölliker anführt, eine solche Annahme ebenfalls zulässig erscheinen lassen könnte.“

Schliesslich nimmt Flemming auch gegenüber Weigert (1896) Stellung, welcher die Bildung der Intercellularsubstanzen für einen "katabiotischen "Prozess und diese Substanz selbst für ebenso leblos, wie eine verhornte Oberhautzelle oder eine pflanzliche Zellmembran erklärt. "Ich sehe", sagt Flemming, „durchaus keinen zwingenden Grund, die Intercellularsubstanzen in solcher Art zu Grabe zu tragen. Weigert gibt als solchen Grund an, dass diese Substanzen Albuminoide und keine Eiweisskörper mehr seien, "was sie doch als lebende Substanzen sein mïssten "; sie beständen aus einem viel weniger labilen Material als diese. In diesem Schluss kann ich meinem hochverehrten Kollegen nicht folgen. Ich sehe nicht ein, warum der Begriff des Lebens notwendig an die Marke "Eiweiss- 
körper" geknüpft sein muss; ich gebe rollkommen zu, dass die lebendigen Stoffwechselvorgänge, wenn sie auch in den Intercellularsubstanzen spielen, hier viel träger sein werden als in den Zellen; dass sie aber in den ersteren fehlen sollten, daran habe ich nie gedacht und möchte einen Beweis dafür doch erst abwarten. Weigert scheint einen solchen darin sehen zu wollen, dass die feinen Formteile der Intercellularsubstanzen (also z. B. Fibrillen und elastische Fasern) sich post mortem lange in der Form erhalten, die Eiweisskörper nicht. Das kommt aber ganz auf die Behandlung an. Ein Stück Leder würde sich auch nicht so erhalten, wenn es nicht gegerbt wäre. In einer Mumie sind die aus Eiweisskörpern bestehenden Teile ja auch recht sehr dauernd erhalten, und in einem gut fixierten mikroskopischen Präparat sind die Zellen auf die Dauer ebenso schön konserviert, wie die Fibrillen im Leder. Ich werde natiurlich wegen dieser Konservierung die Fibrillen in einer Schuhsohle so wenig für lebendig halten, als ich Weigert zumuten möchte, dass er einen Rückenmarksschnitt für lebendig hält. Beide Dinge beweisen eben nur, dass wir Körperbestandteile in totem Zustand gut und lange zu erhalten vermögen, sie beweisen aber nichts dagegen, dass diese in beiden Fällen einst gelebt haben können".

Die von Flemming entwickelte Anschauung von der Lebendigkeit und Wachstumsfahigkeit der Intercellularsubstanz ist spater zunacbst von $\mathrm{H}$ an sen und $\mathrm{Sp}$ uler übernommen worden.

Hansen beschrieb (1899) in einem auf der Anatomenversammlung in Tübingen gehaltenen Vortrag ${ }^{1}$ ), dass sich in den $Z$ wischenwirbelscheiben von Kalbsfeten in den tiefern weicheren Partien viele Zellen finden, die noch nackte Zellen sind, in deren Protoplasmakörper und Zellausläufern sich reichliche Bindegewebsfasern entwickelt haben (vergl. hierzu S. 184). Sowie die Zellen älter werden, umgeben sie sich mit einem Mantel von "Ectoplasma“. „Das Ectoplasma bildet nun auch Bindegewebsfibrillen, und eine Weile findet man gleichzeitig das Endo- und Ectoplasma an deren Bildung beteiligt, aber relativ schnell wird diese Funktion, die Bildung von collagenen Fasern, von der peripheren Schicht, dem Ectoplasma, allein übernommen."

„Die Verhältnisse, welche ich erwahhnt habe, sagt Hansen S. 433, "zeigen, wie mir scheint, unzweifelhaft, dass die Grundsubstanzen ebensogut wie die Zellen als "lebendig“ betrachtet werden müssen, d. $\mathrm{b}$. dass sie innerhalb gewisser Grenzen von den "Zellen" unabhängig "formative Tătigkeit" entfalten können."

1) Der Vortrag, welcher wegen verspäteten Eingangs des Manuskripts in den Verhandlungsberichten keine Aufnahme fand, ist am 5. Oktober 1899 in Bd. 16 des Anatomischen Anzeigers erschienen. 
Einer späteren, 1905 erschienenen Abhandlung von $\mathrm{Hansen}$ über den Hyalinknorpel entnelıme ich folgenden Passus: „Wie mehrmals früher auf meine vorläufigen Mitteilungen über die Entwicklung der Knorpelgrundsubstanzen in Betreff gewisser theoretisch wichtiger Verhältnisse zwischen den "Zellen " und den "Grundsubstanzen" verweisend, hebe ich nur hervor, dass wir dasjenige des Knorpels, was wir gewöhnlich "Knorpelzellen" nennen, als ein Endoplasma zu betrachten haben, während die Grundsubstanz der echten hyalinen Knorpel eventuell als ein gemeinschaftliches und mit Bezug auf das Endoplasma mehr oder weniger selbständiges Ectoplasma aufzufassen ist. In solchen Knorpeln wie dem Faserknorpel und anderen Übergangsformationen lässt sich die Richtigkeit dieser Auffassung klar demonstrieren, die zugleich das Verhalten der "Grundsubstanzen" zu den "Zellen" erhellt. Eine scharfe Sonderung in "Protoplasma", "Zellkörper" und Grundsubstanzen lässt sich in vielen Fallen unmöglich aufrecht erhalten oder nachweisen. Ob man sagt, die "Zelle" "scheide" an ihrer Oberfliche Grundsubstanz "aus" oder "bilde" solche, oder ob man sagt, die peripheren Protoplasmaschichten „verwandelten" sich in Grundsubstanz oder in ein Vorstadium derselben, so bleibt die Tatsache doch die, dass in einer grossen Menge von Fallen irgendwo ein mehr oder weniger umfangreicher, oft direkt nachweisbarer Übergang aus "Protoplasma" in Grundsubstanz angetroffen wird. In einigen Fallen gewahren wir mit unseren jetzigen Hilfsmitteln keinen Übergang, vielleicht weil er überhaupt nicht oder zur Zeit der Untersuchung nicht existiert hat, oder auch weil er sich einstweilen unserem Nachweise entzieht, in anderen Fällen ist es bei sorgfältiger, obne vorhergefasste Meinung, eventuell mit neuen Hilfsmitteln angestellter Untersuchung möglich, sowohl einen Unterschied zwischen z. B. den mehr peripheren "Protoplasmaschichten" und den näher an dem Kerne gelegenen Schichten, wie auch einen Übergang zwischen den peripheren Schichten der Zelle und den innersten Schichten der Grundsubstanz oder den direkten Zusammenhang des Protoplasmas oder gewisser echter Protoplasmabestandteile (z. B. der Filarsubstanz) mit gewissen Elementen der Grundsubstanz, z. B. den Bindegewebs- und elastischen Fibrillen, zu konstatieren."

Auch Spuler sprach sich 1899 in einem Vortrag, der auf 
denjenigen von Hans en folgte, dafür aus, dass man, wie überhaupt bei den Binde- und Stützsubstanzen, beim Knorpel die Bildungen, bevor der Organismus collagene Fasern bildet, von denen unterscheiden müsse, welche sich von dieser Zeit an finden. Im Anfang bilden die Zellen "Aussenzonen“ von Grundsubstanz, welche sich hinterher ablösen und „als selbständig formativer Prozesse făhig zu denken" sind.

Flemming hat dann 1902 in der letzten Abhandlung seines Lebens ( "Histogenese der Stützsubstanzen" in 0. Her t wigs Handbuch der Entwicklungslehre), die er zu einer Zeit geschrieben hat, wo er bereits von schwerem Leiden heimgesucht war, erklikrt, dass er seinerseits der Darstellung von Hansen beitreten möchte.

Flemming schreibt 1902, S. 9: Hansen vertritt in neuester Zeit die Auffassung, dass die produzierende Zelle zunächst einen Mantel von Substanzen an ihrer Peripherie bildet, Ectoplasma von ihm genannt, in welcher sich dann die Fibrillen, unter Umständen auch die elastischen Gebilde, formen. Dieser Auffassung möchte ich beitreten. Und weiter S. 13: - Der neueste Autor über die Entwicklung der Stützsubstanzen ist Fr. C. C. Hansen. Er hat das grosse Verdienst, der definitive Begriinder eine1 Betrachtungsweise $z u$ sein, welche geeignet ist, den Streit zwischen den Anhängern cellulärer und intercellulärer Fibrillenbildung zur Versöhnung zu bringen, so weit wie dies nach dem Obigen überhaupt noch erforderlich scheint. Diese Anschauung - dic im obigen schon mehrfach Erwähnung gefunden hat und der ich mich, wie dort gesagt, anschliessen möchte geht dahin, dass die embryonale Bindesubstanzzelle zunächst an ihrer Peripherie eine mantelförmige Anlagerung bildet, Ectoplasma von $\mathrm{Hansen}$ genannt, welche durch stärkeres Lichtbrechungsvermögen ausgezeichnet ist, und in welcher sowohl Fibrillenbündel als elastische Fasern entstehen können."

In einer Anmerkung dazu sagt Fle mming, ,dass ejgentlich bereits Spuler (1895) die Idee begründet hat, dass die Produktion von Fibrillen nicht bloss von den Zellen selbst, sondern vermittelst von ihnen produzierter "Aussenzonen" in der Grundsubstanz besorgt werden könne". Hier liegt aber von seiten Flemmings offenbar eine Verwechslung mit der Arbeit Spulers aus dem Jahre 1899 vor; denn diejenige aus dem Jahre 1895 enthält nichts auf diesen Gegenstand bezügliches.

Die $\mathrm{H}$ a n se n sche Auffassung, nach welcher die Intercellularsubstanz des Knorpels als „Ectoplasma“ zur Knorpelzelle gehört, könnte in der Tat geeignet erscheinen, uns die Wachstumsfăhigkeit der Intercellularsubstanz verständlicher zu machen. Ich vermag aber meinerseits ebenso wie v. Ebner (1906) diese Aufstellung nicht $z \mathfrak{u}$ acceptieren, da sie meines Erachtens auf irrtümlicher Beobachtung beruht. 
v. Ebner hat bereits 1906 (S. 47) darauf hingewiesen, dass das Ectoplasma Hansens zweifellos bereits gebildete fibrilläre Grundsubstanz ist.

Dieser Ansicht schliesse ich mich an. Ich kann nicht finden, dass es, wie Han sen sagt, Fälle gibt, in denen eine scharfe Sonderung zwischen Knorpelzelle und Grundsubstanz $\mathrm{n}$ i cht zu ziehen sei oder ein Übergang aus Protoplasma in Grundsubstanz angetroffen werde, ebenso wie ich schon oben (S. 184) in Abrede nehmen musste, dass es möglich sei, „einen direkten Zusammenhang des Protoplasmas oder gewisser echter Protoplasmabestandteile (z. B. der Filarsubstanz) mit gewissen Elementen der Grundsubstanz, z. B. den Bindegewebs- und den elastischen Fibrillen zu konstatieren."

Die Anschauung Hansens, welcher auch Studnička (1903) gefolgt ist, läuft darauf hinaus, dass nicht nur die geformte, sondern auch die ungeformte Intercellularsubstanz aus einer direkten Umwandlung der peripheren Protoplasmaschichten hervorgeht. Nach meiner Ansicht aber gehen aus der Zelle direkt nur Fibrillen in die Intercellularsubstanz über, welche sich dann vermehren und eventuell zunächst einen Mantel um die Zelle bilden; die ungeformte Intercellularsubstanz oder Kittsubstanz dagegen wird, soweit sie nicht schon vorher vorhanden ist, nach Art eines Sekrets von den Zellen abgeschieden.

Den Fibrillenmantel kann man mit Flemming $(1897,1)$ als einen metamorphosierten Teil des „Zellenleibes, der als Territorium eigentlich zu diesem Leibe zu gehören fortfährt", auffassen. Insofern könnte man ihn wohl als "Ectoplasma“, die gesamte Intercellularsubstanz als ein „zusammenhängendes Verschmelzungsprodukt der von den Bildungszellen geschaffenen Ectoplasmen" (F lemming, 1902, S. 13) bezeichnen, dürfte dabei aber nicht vergessen, dass es ausschliesslich ein Strukturteil der Zellsubstanz ist, welcher in das „Ectoplasma“ übergeht (allerdings derjenige, welcher in erster Linie „Sitz der vitalen Vorgänge“ ist).

Da Hansen aber mit dem Wort Ectoplasma einen anderen Sinn verbindet, möchte ich meinerseits ebenso wie v. Ebner auf die Anwendung dieses Ausdrucks verzichten.

Soweit die Vermehrungs- und Wachstumsfahigkeit der Bindegewebsfibrillen in Frage kommt, hat $\mathrm{Hansen}$, wie aus dem obigen hervorgeht, nur die Auffassung Flemmings, welche bei 
diesem wahrscheinlich durch v. Ebners Abhandlung (1896) angeregt war, bestätigt. Es ist daher unrichtig, wenn $\mathrm{H}$ an sen vielfach von neueren Autoren als der Begründer dieser Anschauung hingestellt wird. Hansen selbst hat auch niemals einen dahingehenden Anspruch erboben. Er schreibt 1905, S. 751 : „Die Untersuchungen, auf die ich meine oben angeführte Ansicht von der Zelle und der Grundsubstanz begründe, habe ich früher in Kürze dargestellt. Ebendaselbst hob ich kurz hervor und gab ich einige "Beweise" dafür, dass die sogenannter Grundsubstanzen als lebend zu betrachten sind, ebensowohl als die Zellen, d. h. dass sie innerbalb gewisser Grenzen von den Zellen, dem Endoplasma unabhängig eine "formative" Tätigkeit entfalten können. In dieser Beziehung trete ich (von einzelnen, weniger wesentlichen Differenzen abgesehen) völlig den von W. F l e mming gegen Weigert aufgestellten Ansichten bei."

Ich bitte zu beachten, dass $\mathrm{H}$ ansen in obigem Passus das Wort "Beweise“ in Anführungszeichen setzt. In der Tat kann von eigentlichen Beweisen dafür, dass die Fibrillen wachsen, bei Hansen wohl nicht die Rede sein. Solche erblicke ich ausser in meinen eigenen Beobachtungen in denjenigen von v. Ebner (1896), Flemming (1897) und Grönroos (1903), aus welchen hervorgeht, dass die Fibrillen bezw. Fibrillenbündel in starker Vermehrung sein können an Stellen, wo die Zellen spärlich sind oder fehlen. Zur Stütze der Hypothese, dass das Wachstum der Bindegewebsbündel auf dem Wege der Fibrillenspaltung stattfindet, wird ferner von M. Heidenhain (1901，1，S. 38 und 1902 S. 613 und 620) angeführt, dass man auf dem Querschnitt der Bindegewebsbündel jene eigentümliche Aufstellung der Fibrillen trifft, welche das Bild der sogenannten $\mathrm{Cohn}$ h e i m,schen Felderung erzeugt.

Die Tatsache, dass ${ }_{n}$ die Intercellularsubstanz in sich selbst neue Fibrillen hervorbringen kann, " ist nach meiner Meinung noch lange nicht hinreichend gewürdigt worden. Ich glaube, dass z. B. bei der Knorpelbildung dem sekundären Fibrillenwachstum eine viel grössere Bedeutung zukommt, als bisher, z. B. auch von Hansen, angenommen wird. Inmitten der embryonalen Knorpel, aus denen die in meinen Figuren 11-14 wiedergegebenen Zellen stammen, habe ich überhaupt keine Zeichen 
einer von den Zellen ausgehenden Collagenbildung finden können. Das gleiche gilt meines Erachtens für die Knochensubstanz, so lange sie noch unverkalkt ist; nach meinen Beobachtungen produzieren nämlich die Zellen (Osteoblasten) Fibrillen der Hauptsache nach nur so lange, wie sie noch ganz jung und klein sind. Von der verkalkten Knochensubstanz dagegen wissen wir seit den Versuchen von Flourens (1847), dass sie nicht durch "Intussusception “, sondern durch "Apposition“ wächst. ${ }^{1}$ )

Ich habe oben S. 193-194 in Abrede gestellt, dass die Bindegewebsfasern bei ihrer ersten Entstehung aus den Zellen unter dem Eintluss einer Zug- oder Druckspannung stehen; jedoch muss auch nach meiner Meinung angenommen werden, dass bei dem weiteren Wachstum und der Vermelurung der Fibrillen in der Intercellularsubstanz funktionelle Anpassung und Auslese im Sinne von Roux eine massgebende Rolle spielen.

\section{Literaturverzeichnis.}

A rnold, J. (1908): Zur Morphologie des Knorpelglycogens und zur Struktur der Knorpelzellen. Virchows Arch. f. path. Anat., Bd. 194.

Benda, C. (1899): Weitere Mitteilungen über die Mitochondria. Verh. d. Physiol. Ges. zu Berlin, Jahrg. 1898/99.

Derselbe (1902): Über den feineren Bau der glatten Muskelfasern des Menschen. Verh. d. anat. Ges, Halle a. S.

Boll, Franz (1872): Untersuchungen über den Bau und die Entwicklung der Gewebe. Zweite Abteilung. Arch. f. milkr. Anat., Bd. 8.

Bruni, A. C. (1909): Contributo alla conoscenza dell' istogenesi delle fibre collagene. R. Accad. delle Scienze di Torino, anno 1908/09.

Ooca, Arthur F. (1906): Die Bedeutung der „Fibroglia"-Fibrillen. Eine embryologische Studie. Virchows Archiv, Bd. 186.

Dants chak off, Wera (1908): Untersuchungen über die Entwicklung von Blut und Bindegewebe bei Vögeln. Das lockere Bindegewebe des Hühnchens im fetalen Leben. Arch. f. mikr. Anat. u. Entwicklungsgesch., Bd. 73.

1) Was die Knochenbildung anlangt, so sei noch bemerkt, dass ich einerseits der Kritik, welche Nowik off (Zeitschr. f. wiss. Zool., Bd. 92, 1909, S. 42) und N e u g e b a u er (Anat. Hefte, Bd. 40, 1909) an einer neuerdings ausgesprochenen Hypothese geübt haben, durchaus beistimme; andererseits kann ich auch nicht glauben, wie aus dem oben gesagten ohne weiteres hervorgeht, dass die Darstellung, welche Disse (1909) gegeben hat, zu Recht besteht. 
Disse, J. (1909): Die Entstehung des Knochengewebes und des Zahnbeins. Ein Beitrag zur Lehre von der Bildung der Grundsubstanzen. Arch. f. mikr. Anat., Bd. 73.

Duesberg, J. (1909): Über Chondriosomen und ihre Verwendung zu Myofibrillen beim Hühnerembryo. Verh. d. anat. Ges. in Giessen.

v. Ebner, V. (1896): Die Chorda dorsalis der niederen Fische und die Entwicklung des fibrillären Bindegewebes. Zeitschr. f. wiss. Zool, Bd. 62,1897 .

Derselbe (1906): Über die Entwicklung der leimgebenden Fibrillen, insbesondere im Zahnbein. Sitzgsber. d. Kais. Akad. der Wiss. in Wien, math.-naturw. Kl., Bd. 11o, Abt. 3.

Fl e mming, W. (1882): Zellsubstanz, Kern und Zellteilung.

Derselbe (1891): Zur Entwicklungsgeschichte der Bindegewebsfibrillen. Internat. Beitrüge z. wissensch. Medizin, Festschr. f. R. Virchow.

Derselbe (1895): Zelle. Ergeb. d. Anat. u. Entwicklungsgesch., Bd. 4, 1894.

Derselbe (1897) 1: Über den Bau der Bindegewebszellen und Bemerkungen über die Struktur der Zellsubstanz im Allgemeinen. Zeitschr. f. Biologie. Bd. 34, N. F. 16.

Derselbe (1897) 2: Über die Entwicklung der collagenen Bindegewebsfibrillen bei Amphibien und Säugetieren. Arch. f. Anat. u. Physiol., anat. Abt.

Derselbe (1897) 3: Morphologie der Zelle. Ergeb. d. Anat. u. Entwicklungsgesch., Bd. 6, 1896.

Derselbe (1902): Die Histogenese der Stützsubstanzen der Bindesubstanzgruppe. Handbuch d. vergleich. u. experiment. Entwicklungsgesch. d. Wirbeltiere, heransgeg. v. O. Hertwig, Bd. 3.

Goldschmidt, R. (1909): Das Skelett der Muskelzelle von Ascaris nebst Bemerkungen über den Chromidialapparat der Metazoenzelle. Arch. f. Zellforschg., Bd. 4.

Golgi, C. (1898): Sur la structure des cellules nerveuses. Arch. ital. de Biol., t. 30.

Golowinski, J. (1907): Zur Kenntnis der Histogenese der Bindegewebsfibrillen. Anat. Hefte, Abt. 1, Bd. 33.

Grönroos, H. (1903): Bindegewebe ohne Bindegewebszellen. Anat. Hefte, Abt. 1, Bd. 22.

Hansen, Fr. C. C. (1899): Über die Genese einiger Bindegewebsgrundsubstanzen. Anat. Anz., Bd. 16.

Derselbe (1905): Untersuchungen über die Gruppe der Bindesubstanzen. I. Der Hyalinknorpel. Anat. Hefte, Abt. 1, Bd. 27.

Heidenhain, M. (1900): Über die Zentralkapseln und Pseudochromosomen in den Samenzellen von Proteus, sowie über ihr Verhältnis zu den Idiozomen, Chondromiten und Archoplasmaschleifen. Anat. Anz., Bd. 18.

Derselbe (1901) 1: Über die Struktur des menschlichen Herzmuskels. Anat. Anz., Bd. 20.

Derselbe (1901) 2 : II. Struktur der kontraktilen Materie. Erg. d. Anat. u. Entwicklungsgesch., Bd. 10, 1900.

Derselbe (1902): Das Protoplasma und die kontraktilen Fibrillärstrukturen. Eine Antwort an Herrn Professor Apáthy in Klansenburg. Anat. Anz., Bd.21. 
Henle, J. (1841): Allgemeine Anatomie.

จ. Kölliker, A. (1897): Die Energiden von v. Sachs im Lichte der Gewebelehre der Tiere. Würzburger Verhandl., N. F. Bd. 31.

Laguesse, E. (1903) 1: Sur la structure de la capsule de la rate chez l'Acanthias. C. R. de la Société de Biologie, t. 55.

Derselbe (1903) 2: Sur l'histogénèse de la fibre collagène et de la substance fondamentale dans la capsule de la rate chez les Sélaciens. Arch. d'anat. micr., t. 6 .

Derselbe (1903) 3: Sur la substance amorphe du tissu conjonctif lâche. C. R. de la Société de Biologie, t. 55 .

Derselbe (1904) 1: Substance amorphe et lamelles du tissu conjonctif lâche. C. R. de 1'Assoc. des Anat., Toulouse.

Derselbe (1904) 2: Développement des lamelles du tissu conjonctif lâche. C. R. de la Société de Biologie, t. 57 .

Loewenthal, N. (1907): Zur Kenntnis der Knorpelzellen. Anat. Anz., Bd. 30 .

Lwoff, B. (1889): Über die Entwicklung der Fibrillen des Bindegewebes. Sitzgsber. d. Kais. Akad. d. Wiss. Math.-naturw. Kl., Bd. 98, Abt. 3.

Mal1, F. (1891): Das reticulierte Gewebe und seine Beziehungen zu den Bindegewebsfibrillen. Abhandl. d. math.-phys. Kl. d. Kgl. sächs. Ges. d. Wiss. Bd. 17.

Derselbe (1902): On the developement of the connective tissues from the connective-tissue syncytium. Amer. Journ. of Anatomie, vol. 1.

Mallory, F. B. (1903): A hitherto undescribed fibrillar substance produced by connective-tissue cells. Journ. of medical research, rol. 10, Boston 1903/04.

Derselbe (1904): A contribution to the classification of tumors. Journ. of medical research, vol. 13, Boston 1904/05.

Maximow, A. (1906): Über die Zellformen des lockeren Bindegewebes. Arch. f. mikr. Anat. u. Entwicklungsgesch., Bd. 67.

Mc Gill, Caroline (1908): Fibroglia Fibrils in the Intestinal Wall of Necturus and their Relation to Myofibrils. Internat. Monatsschr. f. Anat. u. Physiol., Bd. 25.

MerkeI, Fr. (1893): Über das Bindegewebe der Nabelschnur. Verh. d. Gesellsch. d. Naturforscher u. Ärzte, Nürnberg.

Derselbe (1895) : Zur Histogenese des Bindegewebes. Verh. d. anat. Gesellsch., 9. Versamml., Basel.

Derselbe (1909): Betrachtungen über die Entwicklung des Bindegewebes. Anat. Hefte, Abt. 1, Bd. 38.

Meves, Friedr. (1896): Über die Entwicklung der männlichen Geschlechtszellen von Salamandra maculosa. Arch. f. mikr. Anat. u. Entwicklungsgesch., Bd. 48, 1897.

Derselbe (1907) 1: Die Spermatocytenteilungen bei der Honigbiene (Apis mellifica L.), nebst Bemerkungen über Chromatinreduktion. Arch. f. mikr. Anat. u. Entwicklungsgesch., Bd. 70. 
Meves, Friedr. (1907) 2: Über Mitochondrien bezw. Chondrioconten in den Zellen junger Embryonen. Anat. Anz., Bd. 31.

Derselbe (1907) 3: Die Chondrioconten in ihrem Verhältnis zur Filarmasse Flemmings. Anat. Anat., Bd. 31.

Derselbe (1908): Die Chondriosomen als Träger erblicher Anlagen. Cytologische Studien am Hühnerembryo. Arch. f. mikr. Anat. u. Entwicklungsgesch., Bd. 72.

Nowik off, M. (1909): Über den Chromidialapparat in den Zellen des. Subradularknorpels von Haliotis tuberculata. Anat. Anz., Bd. 34,

Pensa, A. (1901): Osservazioni sulla struttura delle cellule cartilaginee. Boll. della Società Medico-chirurgica di Pavia.

Ranvier, L. (1875): Traité technique d'histologie.

Reinke, F. (1894): Zellstudien. Arch. f. mikr. Anat., Bd. 43.

Renaut, J. (1903) 1: Sur la tramule du tissu conjonctif. C. R. de l'Assoc. des Anat., Liège.

Derselbe (1903) 2: Sur la tramule du tissu conjonctif. Arch. d'anat. micr., t. 6.

Retterer, Ed. (1902): Parallèle des ganglions lymphatiques des Mammifères et des Oiseaux. Compt. rend. de l'Assoc. des Anatomistes, Montpellier.

Derselbe (1907): De la structure réticulee de la cellule cartilagineuse. Compt. rend. de la Société de Biol., Paris, t. 63.

Rollet, A. (1871): Von den Bindesubstanzen. Handbuch der Lehre von den Geweben, herausgeg. von S. Stricker, Bd. 1, Kap. 2.

Derselbe (1872) : Über die Entwicklung des fibrillären Bindegewebes. Untersuchung. aus d. phys.-hist. Institut in Graz.

Sch a f f e r, J. (1901): Grundsubstanz, Intercellularsubstanz und Kittsubstanz. Anat. Anz., Bd. 19.

Schwann, Th. (1839): Mikroskopische Untersuchungen über die Übereinstimmung in der Struktur und dem Wachstum der Tiere und Pflanzen.

v. Smirnow, A. E. (1906): Über die Mitochondrien und den Golgischen Bildungen analoge Strukturen in einigen Zellen von Hyacinthus. orientalis. Anat. Hefte, I. Abt., Bd. 32.

Spalteholz, W. (1906): Über die Beziehungen zwischen Bindegewebsfasern und -zellen. Verhandl. d. anat. Ges., Rostock.

Spuler, A. (1895): Über Bau und Entstehung des elastischen Knorpels. Sitzgsber. d. phys.-med. Soc. in Erlangen, Heft 27.

Derselbe (1896): Beiträge zur Histologie und Histiogenese der Binde- und Stiitzsubstanz. Anat. Hefte, Abt. 1, Bd. 7.

Derselbe (1899): Beitrag zur Histiogenese des Mesenchyms. Verh. d. anat. Ges., 12. Vers., Tübingen.

Studnička, F. K. (1903) 1: Schematische Darstellungen zur Entwicklungsgeschichte einiger Gewebe. Anat. Anz, Bd. 22, 1902-03.

Derselbe (1903) 2: Histologische und histogenetische Untersuchungen über das Knorpel-, Vorknorpel- und Chordagewebe. Anat. Hefte, Abt. 1, Bd. 21.

v. Szily, A ur. (1908): Über das Entstehen eines fibrillären Stützgewebes und dessen Verbältnis zur Glaskörperfrage. Anat. Hefte, Abt. 1, Bd. 35. 
Unna, P. (1895): Über die neueren Protoplasmatheorien und das Spongioplasma. Vortrag in d. biolog. Abt. des Hamburger ärztl. Vereins. Deutsche Medizinalzeitung, Nr. 98-100.

Van der Stricht, 0 . (1889): Recherches sur la structure de la substance fondamentale du tissu osseux. Arch. de Biologie, t. 9.

Derselbe (1892): Contribution à l'étude de la sphère attractive. Arch. de Biologie, t. 12.

Wald e y er, W. (1895): Üher Bindegewebszellen, insbesondere über Plasmazellen. Sitzgsber. d. Kgl, preuss. Akad. d. Wiss. zu Berlin.

Weigert, C. (1896): Neue Fragestellungen zur pathologischen Anatomie. Deutsche med. Wochenschrift.

Z a charia dès, P. A. (1898) 1: Du développement de la fibrille conjonctive. C. R. de l'Acad. des Sciences, t. 126, 1.

Derselbe (1898) 2: Recherches sur le développement du tissu conjonctif. C. R. de la Société de Biologie.

\section{Erklärung der Abbildungen auf Tafel II und III.}

Die Figuren der Tafel II und III sind mit $\mathrm{Z}$ e is s Apochromat $2 \mathrm{~mm}$ (Apertur 1,30 oder 1,40) und Kompensationsocular 12 unter Benutzung des $A$ b b e schen Zeichenapparates entworfen. Der Abstand der Zeichenebene von der Ebene des Tisches betrug $17^{1 / 2} \mathrm{~cm}$. Sümtliche Figuren sind nach Schnitten durch die unteren Extremitäten von Hühnerembryonen gezeichnet. Die Extremitäten waren mit $\mathrm{Fl}$ e m ming schem Gemisch von der oben angegebenen Zusammensetzung fixiert, die Schnitte mit Eisenhämatoxylin gefärbt, diejenigen, nach welchen die Figuren der Tafel III gezeichnet sind, ausserdem noch mit Süurefuchsin nachgefärbt worden.

\section{Tafel II.}

Fig. 1. Aus einem Schnitt durch die untere Extremität eines Embryos von 6 Tagen; links Ectoderm, rechts davon Zellsyncytium des Mesenchyms.

Fig 2. Randpartie einer Sehne von einem sechstägigen Embryo.

Fig. 3. Teil eines Querschnitts durch den Unterschenkel eines achttägigen Embryos. Text S. 153.

Fig. 4. Flachschnitt durch die tiefere Lage des Coriums vom Mittelfuss eines zehntägigen Embryos.

Fig. á a-e. Zellen in verschiedenen (aufeinanderfolgenden) Stadien der Mitose, aus dem Coriumdes Mittelfusses eines zehntägigen Embryos. Text S. 154 .

Fig. 6-8. Aus Flachschnitten vom Unterschenkel eines zehntägigen Embryos. In Fig. $8 \mathrm{Kern}$ in Mitose. Text S. 154.

Fig. 9 u. 10. Zwei lang spindelförmige Bindegewebszellen aus der tieferen Schicht des Coriums von einem 14 tägigen Embryo. 
Fig. 11-14. Knorpelzellen aus Skelettstücken der Extremitäten von sechsbis zehntägigen Embryonen.

Fig. 15. Teil eines Querschnitts durch den Metatarsus eines zehntägigen Embryos. Perichondrale Knochenschale (noch unverkalkt) und Periost.

Fig. 16. Längsschnitt durch einen Knochenbalken, von der Tibia eines 14 tägigen Embryos.

\section{Tafel III.}

Fig. 17-20. Längsschnitte durch Sehnen der unteren Extremität von einem achttägigen Embryo. Fig. 17 aus der Nähe der Extremitätenspitze, Fig. 18-20 aus weiter proximal gelegenen Teilen derselben Extremität.

Fig. 21. Längsschnitt durch Sehne der unteren Extremität eines 14 tägigen Embryos.

Fig. 22-27. Teile von Sehnenquerschnitten, Fig. 22-24 von einem achttägigen, Fig. 25 von einem zwölftägigen, Fig. 26 von einem 14 tägigen, Fig. 27 von einem 19 tägigen Embryo.

Fig. 28. Aus einem Querschnitt durch den Unterschenkel eines achttägigen Embryos. Rand der Fibula: Knorpel rosa, perichondrale Knochenschale (noch unverkalkt) rot und Periost. Das Rosa des Knorpels (rechts) sollte als homogene Fläche erscheinen, ist aber von dem Lithographen, um eine weitere Platte zu sparen, gekörnt (durch Körner des schon in der Tafel enthaltenen Rot) wiedergegeben worden. 


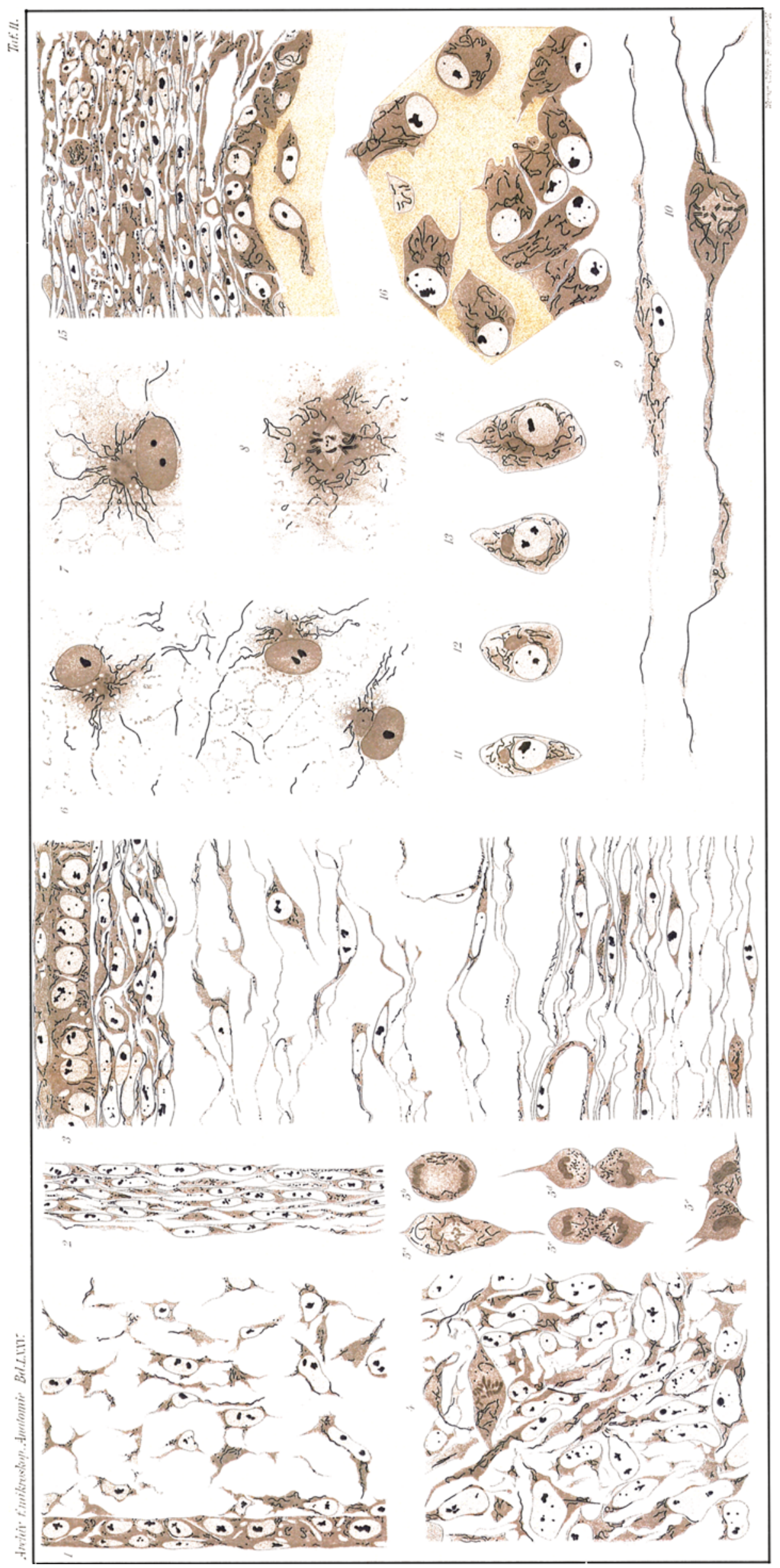




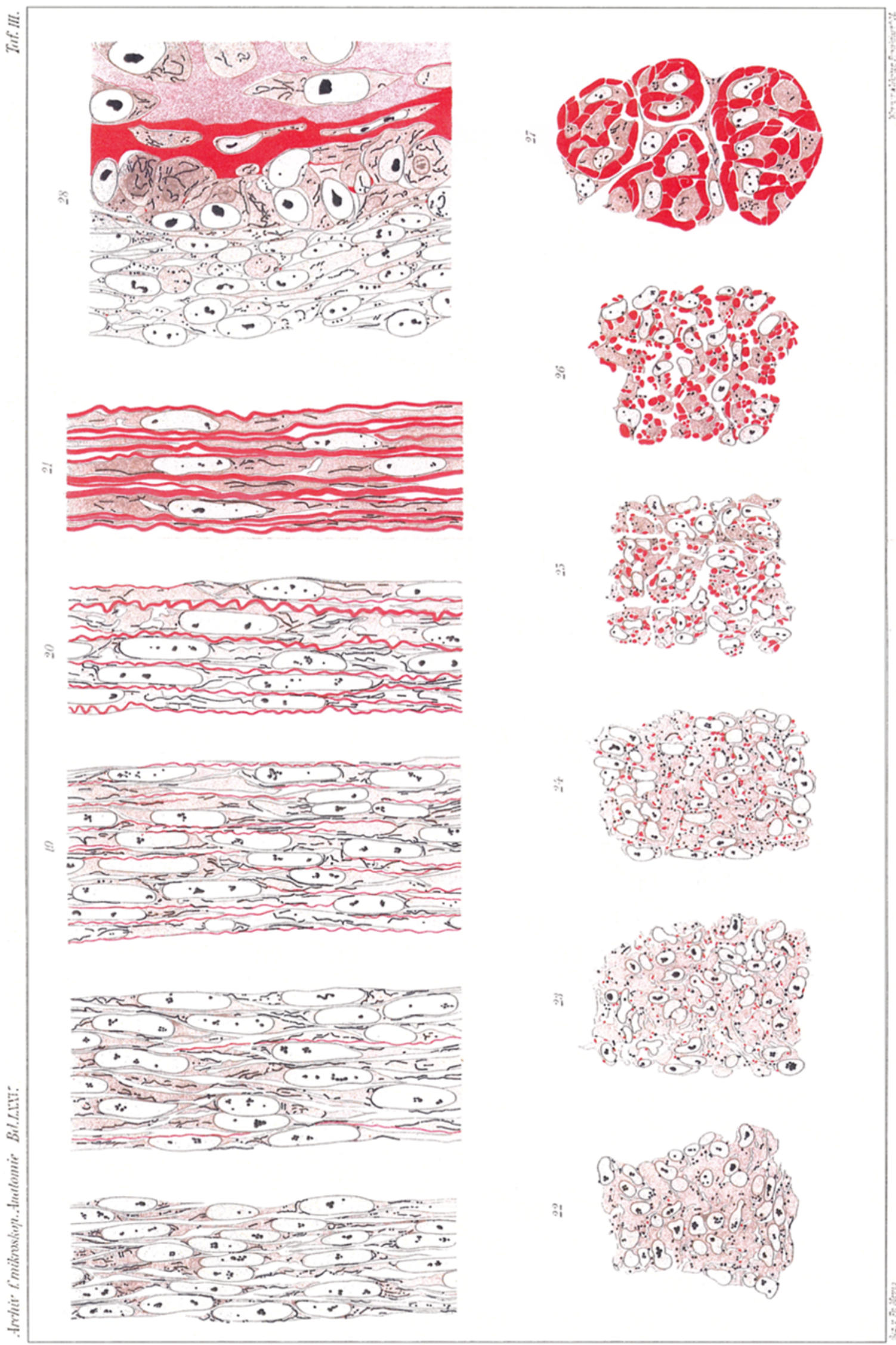

